\title{
Presence of intestinal Mycobacterium avium subspecies paratuberculosis (MAP) DNA is not associated with altered MMP expression in ulcerative colitis
}

Timo Rath ${ }^{1}$, Martin Roderfeld ${ }^{1}$, Sonja Blöcher ${ }^{1}$, Annika Rhode ${ }^{1}$, Tina Basler ${ }^{2}$, Ömer Akineden $^{3}$, Amir Abdulmawjood ${ }^{3}$, Jörg M Halwe ${ }^{4,5}$, Ralph Goethe ${ }^{2}$, Michael Bülte ${ }^{3}$ and Elke Roeb ${ }^{1 *}$

\begin{abstract}
Background: Mycobacterium avium subspecies paratuberculosis (MAP) is suspected to be a causative agent in human Crohn's disease (CD). Recent evidence suggests that pathogenic mycobacteria and MAP can induce the expression of Matrix Metalloproteinases (MMP), which are the main proteases in the pathogenesis of mucosal ulcerations in inflammatory bowel disease (IBD). Within this study we assessed the prevalence of intestinal MAP specific DNA in patients with Crohn's disease, ulcerative colitis (UC), and healthy controls. We further analysed regulation patterns of MMPs in mucosal tissues of UC patients with and without intestinal MAP DNA detection.

Methods: Colonic biopsy samples were obtained from 63 Norwegian and German IBD patients and 21 healthy controls. RNA was quantified by quantitative real-time polymerase chain reaction (PCR) to study MMP gene expression in both pathological and healthy mucosal specimens. The presence of MAP DNA in colonic mucosa was examined using MAP specific PCR.

Results: MAP DNA was detected in 20\% of UC patients and 33\% of healthy controls but only in $7 \%$ of patients with CD. UC patients treated with corticosteroids exhibited a significantly increased frequency of intestinal MAP DNA compared to those not receiving corticosteroids. Expression of MMP-1, -2, -7, -9, -13, -19, -28 and TNF- $\alpha$ did not differ between UC patients with presence of intestinal MAP DNA compared to those without. MMP-2, MMP-9 and MMP-13 were significantly decreased in UC patients receiving corticosteroids.

Conclusions: The presence of intestinal MAP specific DNA is not associated with altered MMP expression in UC in vivo. Corticosteroids are associated with increased detection of intestinal MAP DNA and decreased expression of certain MMPs. Frequent detection of MAP DNA in healthy controls might be attributable to the wide environmental distribution of MAP and its presence in the food-chain.
\end{abstract}

\section{Background}

Mycobacterium avium strains are widely distributed in the environment and inhabit animal and human intestines. Mycobacterium avium subsp. paratuberculosis (MAP) is the causative agent of Johne's disease, a chronic granulomatous inflammation of the intestines in ruminants like dairy cows and many other species, including primates [1].

\footnotetext{
* Correspondence: elke.roeb@innere.med.uni-giessen.de 1 Department of Gastroenterology, Medical Clinic II, Justus Liebig University, Paul-Meimberg-Strasse 5, 35392 Giessen, Germany

Full list of author information is available at the end of the article
}

Crohn's disease (CD) and ulcerative colitis (UC) represent the major forms of human idiopathic inflammatory bowel disease (IBD). Accumulating evidence suggests that $C D$ results from an excessive mucosal immune response towards intestinal microbes in a genetically susceptible host [2]. Since the initial description of clinical similarities between Crohn's disease and Johne's disease in cattle in 1913 [3], it has been hypothesized that MAP might represent a causative agent in CD. Since then, a number of studies and meta-analyses have reported about a more frequent detection of MAP in

\section{Biomed Central}

(c) 2011 Rath et al; licensee BioMed Central Ltd. This is an Open Access article distributed under the terms of the Creative Commons Attribution License (http://creativecommons.org/licenses/by/2.0), which permits unrestricted use, distribution, and reproduction in any medium, provided the original work is properly cited. 
patients with CD than in controls [4-7]. Nevertheless, it is still a matter of controversy whether MAP represents an etiologic factor for CD or rather a secondary invader of inflamed intestinal mucosa [6,8,9]. So far, in vitro studies have identified increased TNF- $\alpha$ levels in mucosal organ culture supernatants from MAP positive CD patients as well as an increased T-cell proliferation upon incubation of peripheral blood mononuclear cells from CD patients with MAP as pathogenic mechanisms and cellular responses $[10,11]$.

Matrix Metalloproteinases (MMPs) are a family of $\mathrm{Zn}^{2+}$-dependent endopeptidases that are considered to be the most potent proteases in the turnover of the extracellular matrix (ECM) [12]. In addition to their capability of degrading virtually all protein components of the ECM, MMPs regulate a variety of non-matrix substrates such as chemokines, cytokines and growth factors and influence the function and migration of inflammatory cells [12]. They are considered to be the predominant proteases in the pathogenesis of mucosal ulcerations associated with IBD [13-15]. Furthermore, evidence suggests that MMPs are upregulated upon infection with pathogenic mycobacteria and MAP thereby leading to the inflammatory tissue changes associated with mycobacterial infections [16-18].

Within the present study we determined the prevalence of MAP DNA in biopsy samples of patients with $\mathrm{UC}$ and $\mathrm{CD}$ as well as in patients without IBD using highly sensitive and MAP specific PCRs. To analyse a potential regulation of MMP expression by MAP in vivo, we further assessed the colonic expression of a broad MMP spectrum in UC patients with and without intestinal MAP DNA detection.

\section{Methods}

\section{Patients and biopsy samples}

From June 2007 to July 2008, biopsy samples were obtained from 63 German $(\mathrm{n}=21)$ and Norwegian $(\mathrm{n}=$ 42) patients with IBD and from 21 German non-IBD patients during diagnostic colonoscopies. Diagnosis of IBD was confirmed clinically and histologically. Biopsies were taken from areas that macroscopically showed the highest degree of inflammation and were in closest proximity to those biopsies taken for histopathological examinations. Additionally samples were taken in areas with milder signs of inflammation or normally (i.e. unaffected) appearing mucosa. The Mayo endoscopic subscore was utilized for the macroscopic classification of the degree of inflammation [19].

Biopsy samples from the German IBD patients $(n=21)$ and the German non-IBD controls $(n=21)$ for MAP culture were placed in a $1.5-\mathrm{ml}$ sterile screw-cap reaction tube containing $0.5 \mathrm{ml}$ of sterile $0.85 \%$ saline and immediately transferred to the laboratory for further investigations. Samples for cultural investigation were not frozen at any time. All biopsies scheduled for MMP analysis were immediately cryopreserved in liquid nitrogen and stored at $-80^{\circ} \mathrm{C}$ until examination. Biopsies underwent a thorough histopathological examination and were classified as "no", "low-grade", or "high-grade" intestinal neoplasia. These examinations were carried out by an experienced pathologist who was neither involved in the study protocol nor aware of the particular MMP measurements. All patients were informed about the study and gave their written consent. In Norway the study was approved by the ethics committee, the data protection commissioner, and the representative for patients' interests and safety (Pasientvernombudet) of the University Bergen. The Norwegian health authority (Helsedirektorat) authorised both, the study and the shipping of the tissue samples from Stavanger, Norway, to Giessen, Germany. In Giessen the study was approved by the local ethic committee (No 75/2009).

\section{Culture of biopsy specimens for MAP detection}

The biopsy specimens from 21 German patients with IBD and 21 non-IBD patients was decontaminated when fresh and subsequently cultured in separate MGIT culture tubes at $37^{\circ} \mathrm{C}$ for up to 18 months. Briefly, $0.5 \mathrm{ml}$ of $\mathrm{NaOH}-\mathrm{N}$ acetyl-L-cysteine (Merck, Darmstadt, Germany) was added to each sample in $0.5 \mathrm{ml}$ of saline, and the mixture was incubated at room temperature for $20 \mathrm{~min}$ with occasional mixing by inversion. The samples were then centrifuged $(10,000 \times g$ for $10 \mathrm{~min})$, and the supernatant was removed. The pellet was resuspended in $0.5 \mathrm{ml}$ of PBS $(14.6 \mathrm{mM}$ $\mathrm{KH}_{2} \mathrm{PO}_{4}, 2 \mathrm{mM} \mathrm{Na} \mathrm{HPO}_{4}$ [pH 6.8]) and transferred to the tube containing $4.5 \mathrm{ml}$ of MGIT medium (Becton Dickinson, Heidelberg, Germany) supplemented with 10\% oleic acid-albumin-dextrose-catalase (OADC), PANTA (40 $\mathrm{U}$ of polymyxin B per $\mathrm{ml}, 4 \mu \mathrm{g}$ of amphotericin B per $\mathrm{ml}, 16 \mu \mathrm{g}$ of nalidixic acid per $\mathrm{ml}, 4 \mu \mathrm{g}$ of trimethoprim per $\mathrm{ml}, 4 \mu \mathrm{g}$ of azlocillin per $\mathrm{ml}$ [final concentrations]), and $2 \mu \mathrm{g}$ of mycobactin J (Allied Monitor, Fayette, MO, USA) per ml. After incubation at $37^{\circ} \mathrm{C}$ for 12 and 52 weeks, the cultures were mixed and $0.5 \mathrm{ml}$ was taken aseptically for testing by the MAP specific PCR as described below. MGIT cultures with visible growth or with a positive PCR result were subcultured onto Herrold's Egg Yolk Medium with ANV (Ampothericin B, Nalidixic acid, Vancomycin) and Mycobactin J and incubated at $37^{\circ} \mathrm{C}$ for up to 12 months. Biopsy samples from Norwegian patients $(n=42)$ were processed for direct specific PCR testing.

\section{DNA extraction and PCR analysis for MAP detection}

The DNA of the biopsy samples and MGIT cultures after 12 and 52 weeks was extracted using a modified protocol of the DNeasy Blood and Tissue Kit (Qiagen, Hilden, Germany) for the extraction of DNA from 
Gram-positive bacteria. As a modification to the protocol of the DNeasy Blood and Tissue kit, samples were processed in a spin/rotation instrument for cell lysis (FastPrep-120), with a speed and time setting of 6 and 45 seconds, respectively.

For the molecular detection of MAP, two PCR systems were set up in parallel, a triplex real time-PCR targeting MAP specific genes F57 and ISMav2 and an internal amplification control (IAC) [20], and a nested PCR [21] with IS900 oligonucleotide primers. The PCR reaction mixture for the nested PCR $(50 \mu \mathrm{l})$ contained $1 \mu \mathrm{l}$ primer $1(10 \mathrm{pmol} / \mu \mathrm{l}), 1 \mu \mathrm{l}$ primer $2(10 \mathrm{pmol} / \mu \mathrm{l}), 1 \mu \mathrm{l}$ dNTP (10 mmol, Roche), $5 \mu \mathrm{l} 10 \times$ thermophilic-buffer (Applied Biosystems, Darmstadt, Germany), $0.5 \mu \mathrm{l}$ $\mathrm{MgCl}_{2}$ (25 mM, Applied Biosystems), $0.5 \mu \mathrm{l}$ Ampli Taq Gold DNA polymerase ( $5 \mathrm{U} / \mu \mathrm{l}$, Applied Biosystems) and $36 \mu \mathrm{l}$ double-distilled water. Finally, $5 \mu \mathrm{l}$ of the DNA preparation was added to each reaction tube. The triplex real time-PCR assay was performed as previously described [20]. The fluorescent data were generated by TaqMan $^{\circledR}{ }_{\text {mgb }}$ probes applied on the ABI Prism ${ }^{\circledR} 7000$ Sequence Detection System according to the instructions of the supplier. Briefly, the $50 \mu \mathrm{l}$ PCR mixture for the triplex real time-PCR assay consisted of $25 \mu \mathrm{l}$ of the 2xqPCR MasterMix Plus w/o uracil N-glycosylase (UNG, Eurogentec, Seraing, Belgium), $1 \mu \mathrm{l}$ of each primer (F57, ISMav2), $2 \mu \mathrm{l}$ of each of the fluorogenic probes (F57, ISMav2, IAC), $1.5 \mu \mathrm{l}$ of the IAC, $8.5 \mu \mathrm{l}$ of double-distilled water and a $5-\mu \mathrm{l}$ aliquot of the DNA sample. The PCRs were performed in a 96well plate format on the ABI Prism ${ }^{\circledR} 7000$ Sequence Detection System (Applied Biosystems). Thermal cycling conditions comprised a Hot Start DNA Polymerase activation at $95^{\circ} \mathrm{C}$ for 10 minutes, 50 cycles of denaturation at $95^{\circ} \mathrm{C}$ for 15 seconds, and an annealing and extension at $60^{\circ} \mathrm{C}$ for 1 minute. Each measurement was performed in duplicate, and the threshold cycle $(\mathrm{Ct})$ was determined. Primer sequences and fluorogenic probes for MAP detection are presented in Table 1 .

\section{RNA Purification, cDNA Synthesis and RT-PCR for MMP analyses}

Biopsy samples were homogenized with a polytron homogenizer (Kinematica, Luzern, Switzerland) and total cellular RNA was extracted from shock-frozen single biopsies with RNeasy Kit (Qiagen, Hilden, Germany) according to the manufacturer's instructions. Firststrand cDNA was synthesized from $1 \mu \mathrm{g}$ DNA-free total RNA using the oligo-dT-primers and the first-strand cDNA synthesis kit for RT-PCR (Roche Diagnostics, Mannheim, Germany). Real time-PCR was performed using Platinum SYBR Green qPCR Kit (Invitrogen, Karlsruhe, Germany) according to the manufacturer's
Table 1 Oligonucleotide primers and fluorogenic probes for MAP detection

\begin{tabular}{|c|c|c|}
\hline Designation & Sequence & Reference \\
\hline F57 forward & $\begin{array}{l}5^{\prime}-\text { FTA CGA GCA CGC } \\
\text { AGG CAT TC-3' }\end{array}$ & $\begin{array}{l}\text { Schönbrücher } \\
\text { et al. [20] }\end{array}$ \\
\hline F57 reverse & $\begin{array}{l}5^{\prime}-\mathrm{CGG} \text { TCC AGT TCG } \\
\text { CTG TCA T-3' }\end{array}$ & \\
\hline F57 TaqMan ${ }_{\text {mgb }}^{\circledR}$-probe & $\begin{array}{l}\text { VIC -CCTGACCACCC } \\
\text { TTC-MGB }\end{array}$ & \\
\hline F57 TaqMan ${ }^{\circledR}{ }_{m b}-I A C$ & $\begin{array}{l}\text { NED-CGAGTTACA } \\
\text { TGATCCC-MGB }\end{array}$ & \\
\hline ISMav2 forward & $\begin{array}{l}\text { 5'-CGG CAA AAT CGA } \\
\text { GCA GTT TC-3' }\end{array}$ & \\
\hline ISMav2-R reverse & $\begin{array}{l}5^{\prime}-\mathrm{TGA} \text { GCC GGT GTG } \\
\text { ATC ATC } 1 T T-3^{\prime}\end{array}$ & \\
\hline ISMav2 TaqMan ${ }_{\text {mgb }}^{\circledR}$-probe & $\begin{array}{l}\text { FAM-CGC TGA GTT } \\
\text { CCT TAG-MGB }\end{array}$ & \\
\hline TJ1 forward & $\begin{array}{l}5^{\prime}-\text { GCT GAT CGC CTT } \\
\text { GCT CAT-3' }\end{array}$ & Bull et al. [21] \\
\hline TJ2 reverse & $\begin{array}{l}\text { 5'-CGG GAG TाT GGT } \\
\text { AGC CAG TA-3' }\end{array}$ & \\
\hline TJ3 forward & $\begin{array}{l}5^{\prime}-\text {-CAG CGG CTG CTT } \\
\text { TAT ATT CC-3' }\end{array}$ & \\
\hline TJ4 reverse & $\begin{array}{l}5^{\prime}-\text { GGC ACG GCT CTT } \\
\text { GTT GTA GT-3' }\end{array}$ & \\
\hline
\end{tabular}

protocol. Real time-PCR of each gene-specific primer pair was optimized prior to the experiment to confirm the absence of any non-specific amplification product. Primers were purchased from Eurofins (Ebersberg, Germany) and primer sequences are presented in Table 2.

qRT-PCR was performed on the Mx3000P (Stratagene, La Jolla, USA) by using 3-stage program parameters as follows: 1) 10 minutes at $96^{\circ} \mathrm{C}$, 2) 40 cycles of 10 seconds at $95^{\circ} \mathrm{C}, 30$ seconds at $57^{\circ} \mathrm{C}$, and 30 seconds at $73^{\circ} \mathrm{C}$, 3) 10 minutes at $73^{\circ} \mathrm{C}$. The specificity of the PCR was confirmed by examination of the dissociation reaction plot subsequent to $\mathrm{qRT}$-PCR. PCR products were separated on a $1.5 \%$ TAE agarose gel and visualized by staining with ethidium bromide to confirm the appearance of a single band of the correct molecular size. Furthermore, specificity of the PCR reactions and the utilized primers for MMP analyses was verified in sequencing analyses. qRT-PCR data were analysed using the $\Delta \Delta \mathrm{Ct}$ model [22].

\section{Statistical analysis}

Prior to more sophisticated statistical calculations, normal distribution of the data was tested using the Kolmogorov-Smirnov test and visualization of histograms. Failing to meet criteria for normal distribution all data were analysed using non-parametric tests. To compare MAP DNA positive detection rates in the three groups 
Table 2 SYBR Green Real-time qPCR Primer sequences

\begin{tabular}{|c|c|c|}
\hline Gene & Primer Sequence & $\begin{array}{l}\text { GenBank } \\
\text { AccessionNo. }\end{array}$ \\
\hline human MMP-1 & $\begin{array}{l}\text { Fw: 5'-AAG TTG AAA AGC GGA } \\
\text { GAA ATA G-3' } \\
\text { Rev: 5'-TT CAA TCC TGT AGG } \\
\text { TCA GAT G-3' }\end{array}$ & NM 002421 \\
\hline human MMP-2 & $\begin{array}{l}\text { Fw: 5'-GGC AGA CAT CAT GAT } \\
\text { CAA CT-3' } \\
\text { Rev: 5' TGC TGT CAT AGG ATG } \\
\text { TG-3' }\end{array}$ & NG 008989 \\
\hline human MMP-7 & $\begin{array}{l}\text { Fw: 5'-AGT TTA GAA GCC AAA } \\
\text { CTC AAG G-3' } \\
\text { Rev: 5'-GCG GTA AGT CTC GAG } \\
\text { TAT ATG-3' }\end{array}$ & NM 002423 \\
\hline human MMP-9 & $\begin{array}{l}\text { FW: 5'-TTG ACA GCG ACA AGA } \\
\text { AGT GG-3' } \\
\text { Rev: 5'-GTA CAT AGG GTA CAT } \\
\text { GAG CG-3' }\end{array}$ & NG 011468 \\
\hline human MMP-13 & $\begin{array}{l}\text { Fw: 5'-GCA GTC TाT CTT CGG } \\
\text { CTा AG-3' } \\
\text { Rev: 5'-GGA GTT ACA TCG GAC } \\
\text { CAA AC-3' }\end{array}$ & NM 002427 \\
\hline human MMP-19 & $\begin{array}{l}\text { FW: 5'-CTT TCA AGG GGG ACT } \\
\text { ATG TG-3' } \\
\text { Rev: 5'-TAT TCA GCT TCT TGG } \\
\text { GGA AG-3' }\end{array}$ & NM 002429 \\
\hline human MMP-28 & $\begin{array}{l}\text { Fw: 5'-GAG GCA TTC CTA GAG } \\
\text { AAG TAC G-3' } \\
\text { Rev: 5'-CTA GCA AAC AAG TCA } \\
\text { CTG ATC C-3' }\end{array}$ & NM 024302 \\
\hline human TNF- $\alpha$ & $\begin{array}{l}\text { FW: 5'-CAT GTT GTA GCA AAC } \\
\text { CCT CA-3' } \\
\text { Rev: 5'-CTT GGT CTG GTA GGA } \\
\text { GAC G-3' }\end{array}$ & NM 000594 \\
\hline human 18sRNA & $\begin{array}{l}\text { FW: 5'-GAT CAG ATA CCG TCG } \\
\text { TAG TTC C-3' } \\
\text { Rev: 5'-TAT CAA TCT GTC AAT } \\
\text { CCT GTC C-3' }\end{array}$ & NR 003286 \\
\hline
\end{tabular}

CD, UC, and control patients, Fisher's exact test was applied. Individual MMP expression in UC affected colonic mucosa was referred to the respective expression in corresponding healthy mucosa of the same individual in order to account for interindividual differences in colonic MMP expression. Results of MMP expression in relation to the MAP infection status are presented in box-and-whisker-plots. The upper hinge of the box represents the 75 th percentile; the lower hinge represents the 25th percentile. The line in the box indicates the median value of the data. The ends of the vertical lines represent the minimum and maximum. Outliers ( $\square$ ) have a distance from 1.5 to 3 box lengths from the upper or lower hinge. Extreme values $(\Delta)$ have a distance of $>3$ box lengths from the upper or lower hinge. Interindividual comparisons of MMP expression were made using Mann-Whitney-U test. A two-sided $P<$ 0.05 was considered significant. Statistical analysis was performed with SPSS 17.0 (SPSS Inc, Chicago, Ill).

\section{Results}

Demographic and clinical data of the patient cohort

Intestinal biopsies were obtained during routine colonoscopies from adult patients with CD $(\mathrm{n}=14)$, UC ( $n=49)$ and controls without IBD or other inflammatory disorders within the intestines $(n=21)$. Diagnosis of CD and UC was confirmed in accordance with the current guidelines based on histopathological examination and clinical findings. Table 3 summarizes the clinical data of these patients.

\section{Detection of MAP in IBD patients and controls}

None of the MGIT samples were positive for MAP in the cultural investigation after 12 and 52 weeks of culture.

A total of 63 IBD patients and 21 controls were analysed for the presence of MAP specific DNA in

Table 3 Demographical and clinical data of the IBD patient cohort

\begin{tabular}{|c|c|c|}
\hline & UC $(n=49)$ & $C D(n=14)$ \\
\hline \multicolumn{3}{|l|}{ Age (years) } \\
\hline - mean +/-SD & $39.6+/-13.5$ & $32.4+/-13.1$ \\
\hline - range & 19-74 & 20-68 \\
\hline Sex $[$ male/female (n)] & $26 / 23$ & $7 / 7$ \\
\hline \multicolumn{3}{|l|}{ Disease manifestation UC (n) } \\
\hline - rectum & 4 & \\
\hline - rectosigmoid & 19 & \\
\hline - including C. descendens (leftsided colitis) & 9 & \\
\hline - pancolitis & 17 & \\
\hline \multicolumn{3}{|l|}{ Disease manifestation CD (n) } \\
\hline - terminal ileum & & 2 \\
\hline - terminal ileum + colon & & 6 \\
\hline - colon only & & 6 \\
\hline \multicolumn{3}{|l|}{ Endoscopic classification $^{1}(\mathrm{n})$} \\
\hline - mild inflammation & 15 & 4 \\
\hline - moderate inflammation & 27 & 8 \\
\hline - severe inflammation & 7 & 2 \\
\hline \multicolumn{3}{|l|}{ Histopathologic examination (n) } \\
\hline - mild disease activity & 20 & 1 \\
\hline - moderate disease activity & 23 & 8 \\
\hline - severe disease activity & 6 & 1 \\
\hline \multicolumn{3}{|l|}{ Anti-inflammatory therapy $[\mathrm{AIT},(\mathrm{n})]^{2}$} \\
\hline - no AIT & 14 & 1 \\
\hline - AIT & 35 & 13 \\
\hline \multicolumn{3}{|l|}{ substance class } \\
\hline - 5-ASA & 31 & 6 \\
\hline - corticosteroids & 8 & 8 \\
\hline - immunomodulators & 3 & 3 \\
\hline
\end{tabular}

${ }^{1}$ Macroscopic classification of the degree of inflammation was adjusted according to the Mayo endoscopic subscore [19].

${ }^{2}$ Some patients received different substance classes, therefore the summation of patients in the category "substance class" exceeds the number of patients in the category "AIT". 5-ASA: 5-amino salicylic acid and its derivatives, immunomodulators: azathioprine and infliximab. 
colonic mucosa. To exclude locoregional differences in MAP infection, IBD patients from Germany $(\mathrm{n}=21)$ and Norway $(n=42)$ were recruited. Despite a more frequent detection of MAP DNA in UC patients (20\%) and controls (33\%) compared to patients with CD (7\%) in the total patient cohort, differences in MAP frequency between these three groups were not statistically significant (CD vs. controls: $\mathrm{p}=0.1078$, UC vs. controls: $\mathrm{p}=0.3615$, CD vs. UC: $\mathrm{p}=0.4298$ ).

Subgroup analyses considering the German and Norwegian patient cohort separately revealed likewise no significant differences in MAP frequency between patients with $\mathrm{CD}$ and UC and controls (Norway: CD vs. controls: $\mathrm{p}=0.2945$; UC vs. controls: $\mathrm{p}=0.1885$; $\mathrm{CD}$ vs. UC: $\mathrm{p}=$ 1.00 and Germany: CD vs. controls: 0.2216; UC vs. controls: $\mathrm{p}=1.00$; CD vs. UC: 0.3108$)$. Although the MAP detection rate was generally higher in Germany (29\%) than in Norway (14\%), these differences did not reach the level of statistical significance $(\mathrm{p}=0.1828)$. MAP prevalence in the different cohorts is summarized in Table 4.

We next compared whether the frequency of MAP detection in the IBD and UC patient cohort differed depending on the applied anti-inflammatory therapy (AIT). Comparing IBD and UC patients receiving any kind of AIT to those patients without AIT, no statistical significances in MAP frequency were detected (Figure 1, 2). Similarly, no significant differences in MAP DNA prevalence were observed when patients treated with 5-amino salicylic acid (5-ASA) and its derivatives or immunomodulators (azathioprine and infliximab) were compared to those patients without the respective agents. When comparing patients stratified to the treatment with corticosteroids, MAP DNA was significantly more frequently obtained in UC patients treated with corticosteroids compared to those without corticosteroids in their therapeutic regime $(\mathrm{p}=$ 0.043 , Figure 2c). However, although not statistically

Table 4 Frequency MAP DNA detection in IBD patients
and controls
\begin{tabular}{lcc}
\hline Patient cohort $(n)$ & $\begin{array}{c}\text { MAP } \\
\text { positive }(n)\end{array}$ & $\begin{array}{c}\text { MAP } \\
\text { negative }(n)\end{array}$ \\
\hline Control cohort $(n=21)$ & $7(33 \%)$ & $14(67 \%)$ \\
IBD patients Germany & & \\
$-C D(n=10)$ & $1(10 \%)$ & $9(90 \%)$ \\
$-U C(11)$ & $4(36 \%)$ & $7(64 \%)$ \\
IBD patients Norway & $0(0 \%)$ & $4(100 \%)$ \\
$-C D(n=4)$ & $6(16 \%)$ & $32(84)$ \\
$-U C(n=38)$ & $1(7 \%)$ & $13(93 \%)$ \\
\hline IBD patients Norway + Germany & $39(80 \%)$ \\
$-C D(n=14)$ & $10(20 \%)$ & \\
$-U C(n=49)$ &
\end{tabular}

significant, a higher frequency of MAP detection in the corticosteroid group was observed in the total IBD population as well (Figure 1c).

\section{MMP expression in UC patients with and without presence of MAP DNA}

For MMP analyses, all determined mRNA values were related to the respective content of $18 \mathrm{~S}$ rRNA which served as a housekeeping gene. In order to account for interindividual differences in the MMP expression in the colon, MMP expression in diseased colonic mucosa was referred to the respective expression in corresponding healthy mucosa of the same individual.

Gene expression of MMP-1, MMP-2, MMP-7, MMP9, MMP-13 and MMP-19 was unchanged between UC patients with presence of MAP DNA and those without (Figures 3, 4, 5, 6, 7, 8). Mucosal mRNA expression of MMP-28 and TNF- $\alpha$ did not show any dependency on the presence of MAP DNA either (Figures 9 and 10).

As MAP DNA was detected in only one CD patient, we were unable to analyse MMP expression with regard to MAP status in the CD patient cohort. Since endoscopic evaluation of screening colonoscopy did not reveal any signs of intestinal inflammation, MMP regulation in inflamed mucosa expressed as a multiple of basal expression in healthy mucosa could not be performed in the control cohort either.

\section{Effects of anti-inflammatory agents on MMP and TNF- $\alpha$ expression}

To analyse a potential effect of the applied anti-inflammatory therapy on intestinal MMP expression, we further calculated MMP and TNF- $\alpha$ expression in UC patients stratified by the different therapeutic modalities. Gene expression of MMP-1, -2, -7, -9, -13, -19, -28 and TNF- $\alpha$ was unchanged between patients with and without AIT, between patients stratified to 5-ASA and its derivatives and between patients with and without immunomodulators. However, median levels of MMP-2, MMP-9, and MMP-13 were significantly decreased in UC patients treated with corticosteroids compared to those with no corticosteroids in their therapeutic regime (MMP-2: 6.1-fold, $\mathrm{p}=$ 0.024; MMP-9: 4.2-fold, $\mathrm{p}=0.009 ; \mathrm{MMP}-13$ : 9.5-fold, $\mathrm{p}=0.042$, Figures 3, 4, 5, $6,7,8,9,10)$.

Based on this finding, we excluded steroid-treated patients in a further analysis and re-calculated the MMP and TNF- $\alpha$ expression in MAP positive and MAP negative IBD patients. However, despite the nonconsideration of steroid treated patients, expression of MMP-1, -2, -7, -9, -13, -19, -28 and TNF- $\alpha$ remained unchanged between MAP positive and negative IBD patients (Additional Files 1, 2, 3, 4). 

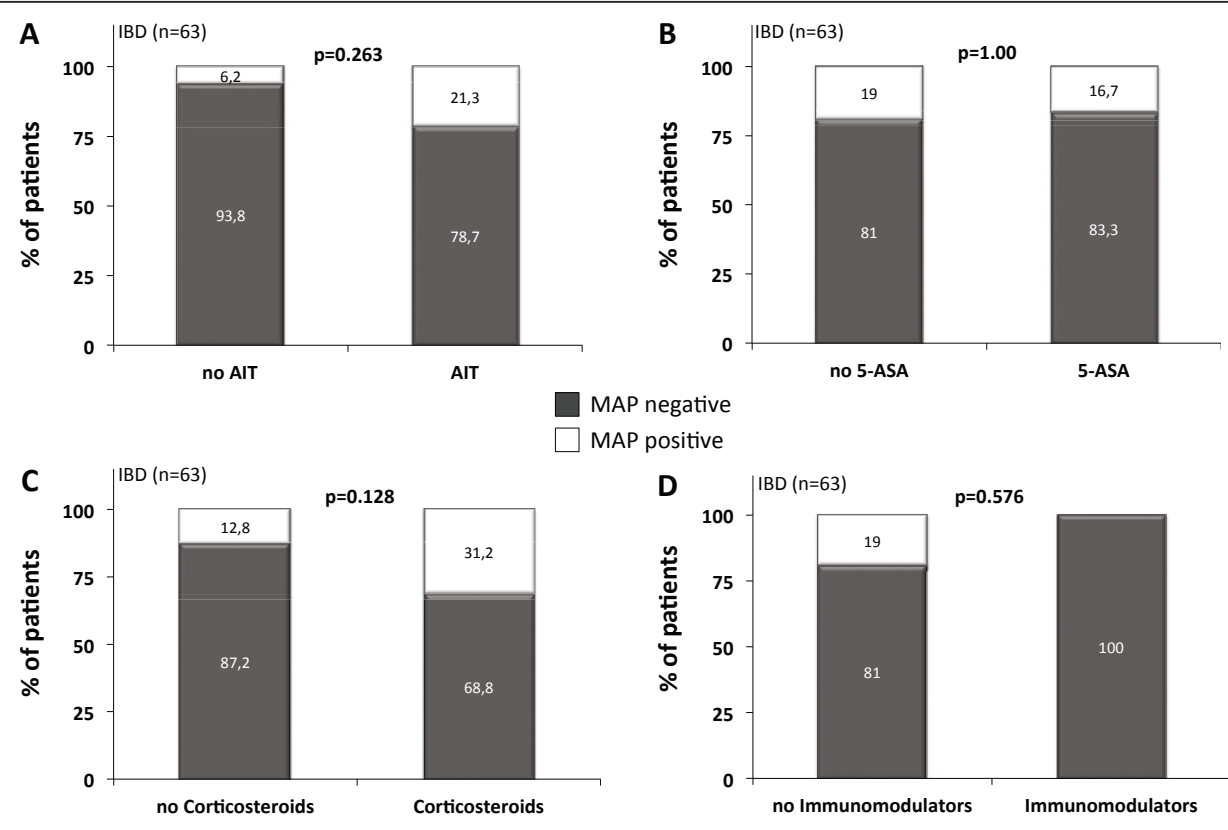

MAP negative

MAP positive

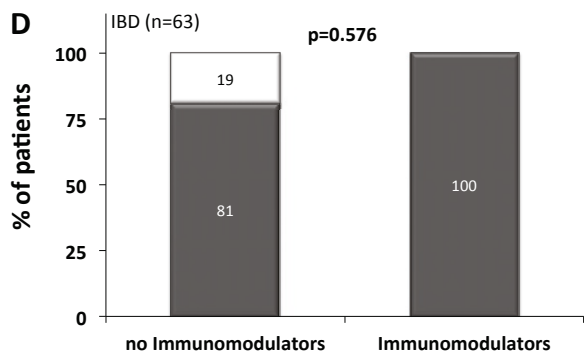

Figure 1 Frequency of intestinal MAP DNA detection in subgroups of IBD patients $(\mathbf{n}=\mathbf{6 3})$. Comparisons were made using Fisher's exact test. For visualization, the number of patients in each subgroup was converted to $100 \%$ and the percentage of MAP positive and negative patients in each subgroup is shown, respectively. Frequency of MAP specific DNA was not altered between IBD patients with anti-inflammatory therapy (AIT) and those without (A). Similarly, there were no differences in MAP frequency between IBD patients treated with 5-amino salicylic acid (5-ASA) and its derivatives (B) or immunomodulators (azathioprine and infliximab, D) and those without the respective agents. Although not statistically significant, MAP DNA was more frequently found in IBD patients treated with corticosteroids compared to those without (C).
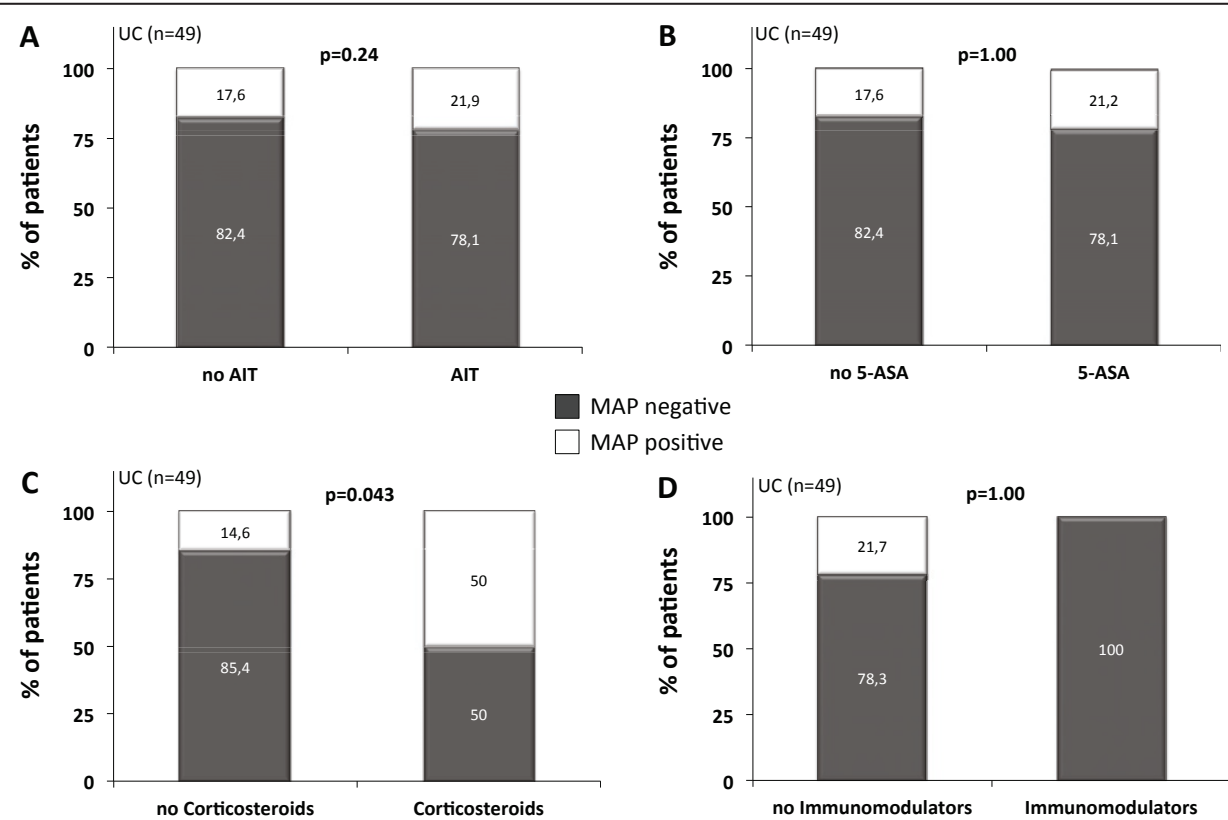

MAP negative
MAP positive

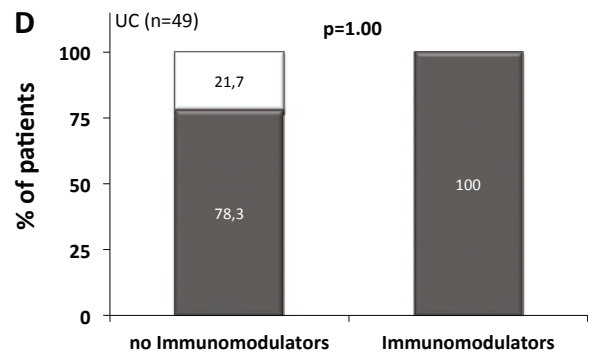

Figure 2 Frequency of intestinal MAP DNA detection in subgroups of UC patients $(\mathbf{n}=\mathbf{4 9})$. Comparisons were made using Fisher's exact test. For visualization, the number of patients in each subgroup was converted to $100 \%$ and the percentage of MAP positive and negative patients in each subgroup is shown, respectively. UC patients treated with corticosteroids had a significantly higher frequency of MAP detection than UC patients receiving no corticosteroids (C) whereas the detection of MAP DNA was not altered between IBD patients with anti-inflammatory therapy (AIT) and those without (A). Frequency of MAP specific DNA was not changed between UC patients treated with 5-amino salicylic acid (5-ASA) and its derivatives (B) or immunomodulators (azathioprine and infliximab, D) compared to those without the respective agents. 

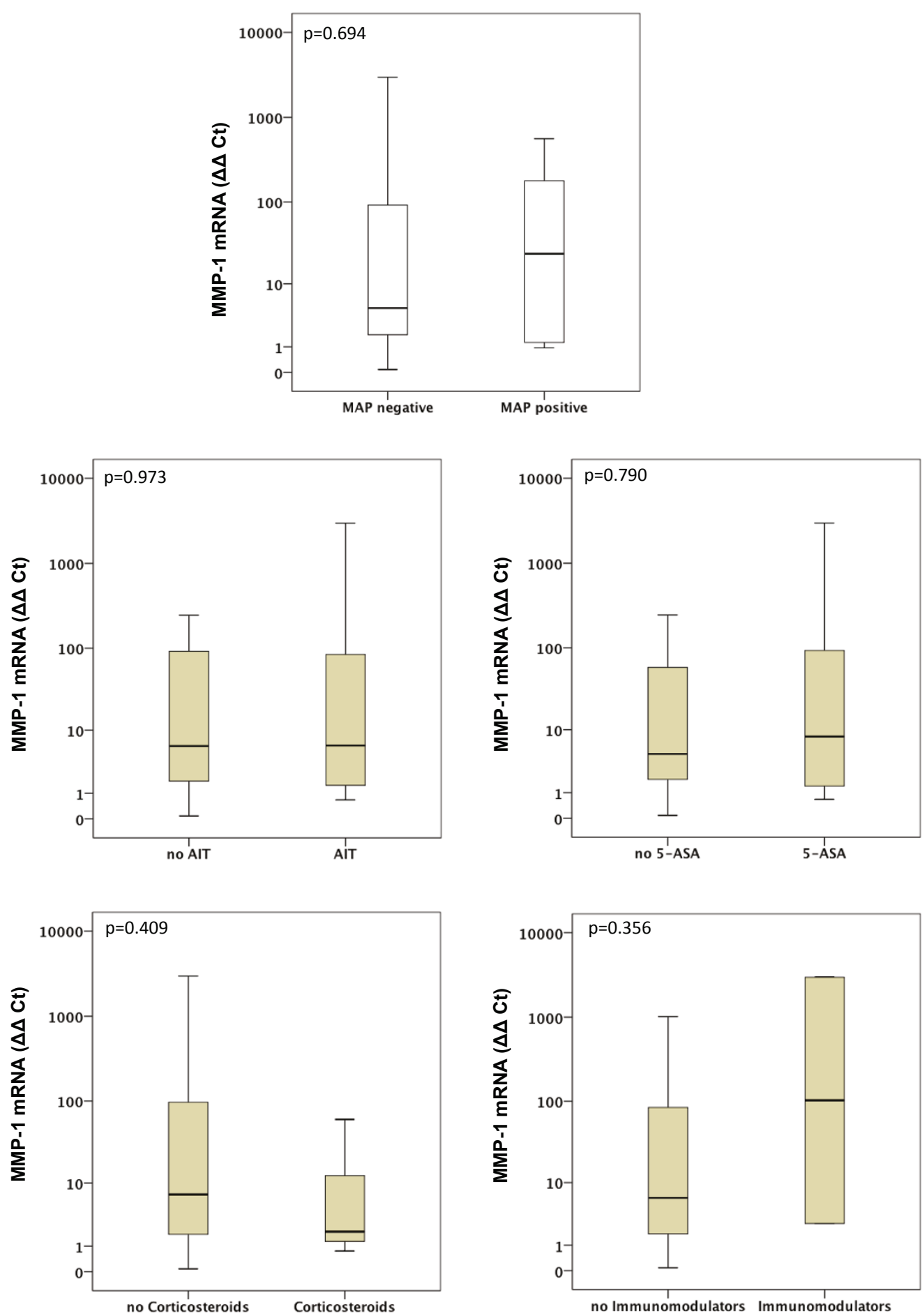

Figure 3 Expression of MMP-1 in UC patients $(\mathbf{n}=\mathbf{4 9}$ ). mRNA results were determined by RT-PCR. MMP-1 gene expression was not significantly different in UC patients with intestinal MAP detection and those without $(p=0.694)$ and did not differ between patients receiving an anti-inflammatory therapy (AIT) and those without AIT ( $p=0.973$ ). Further stratification into subgroups of patients receiving 5 -amino salicylic acid (5-ASA) and its derivatives, corticosteroids or immunomodulators (azathioprine and infliximab) revealed no significant differences in MMP-1 expression between patients treated with the respective substance and those not receiving the respective agent. Note, that some patients received more than one substance class and therefore appear in more than one subgroup. 

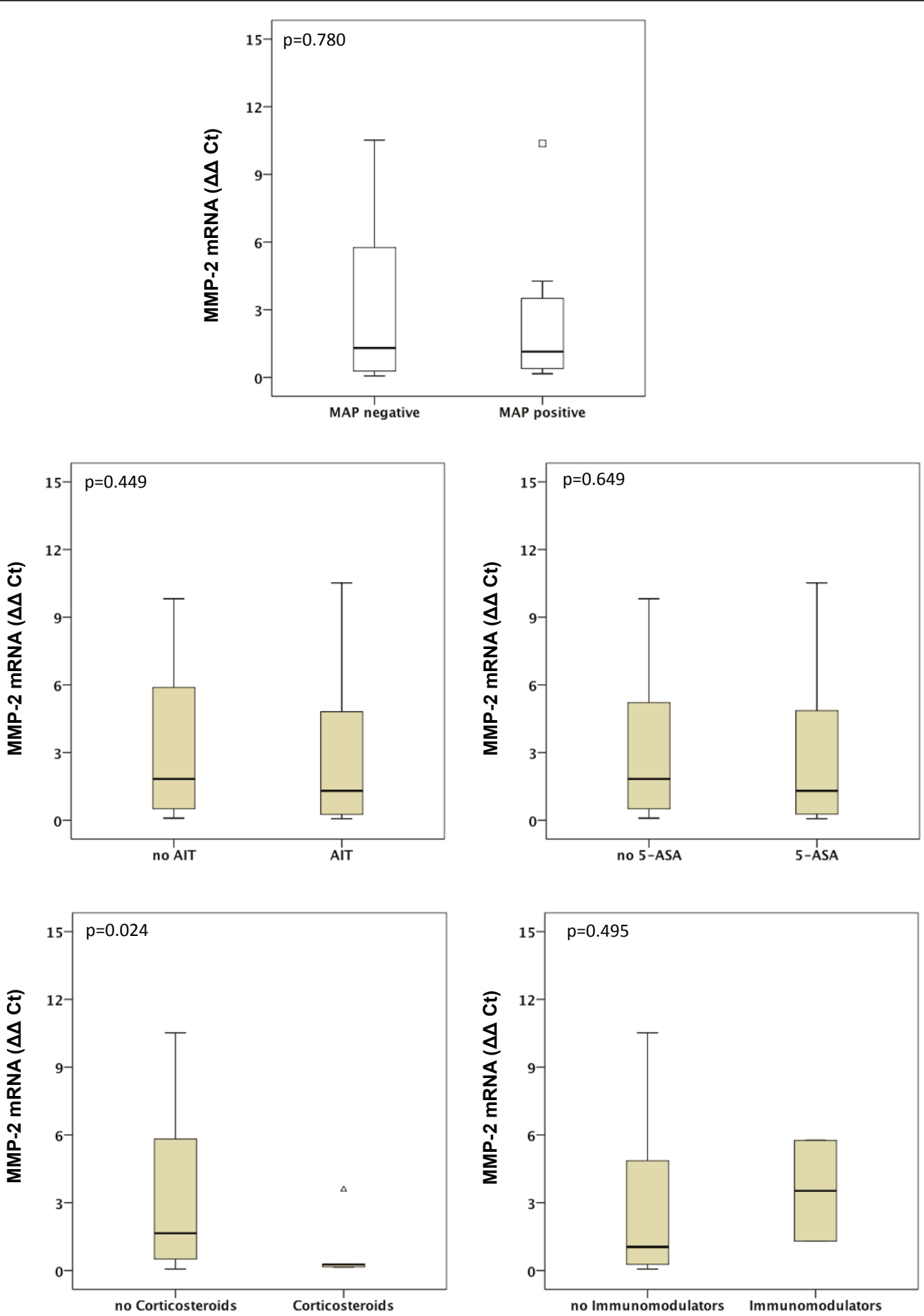

Figure 4 Expression of MMP-2 in UC patients $(\mathbf{n}=\mathbf{4 9})$. mRNA results were determined by RT-PCR. MMP-2 gene expression was not significantly different in UC patients with intestinal MAP detection and those without $(p=0.780)$ and did not differ between patients receiving an anti-inflammatory therapy (AIT) and those without AIT ( $p=0.449$ ). Further stratification of the UC cohort according to the different therapeutic agents revealed that MMP-2 mRNA is significantly decreased by factor 6.1 in UC patients treated with corticosteroids compared to those with no corticosteroids in their therapeutic regime $(p=0.024)$. No differences in MMP-2 expression were observed when patients receiving 5 -amino salicylic acid (5-ASA) and its derivatives or immunomodulators (azathioprine and infliximab) were compared to patients not treated with the respective agent. Note, that some patients received more than one substance class and therefore appear in more than one subgroup. 

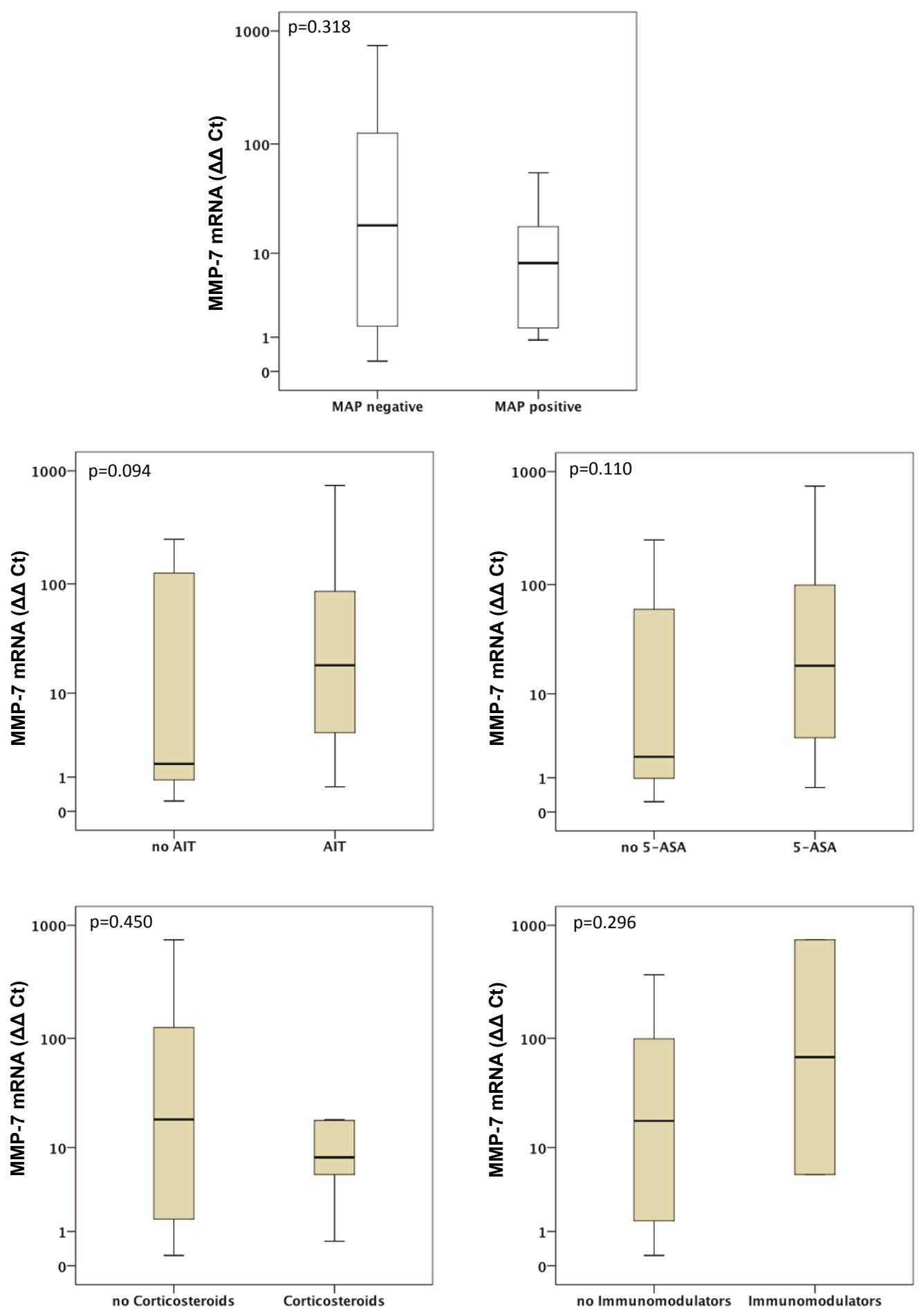

Figure 5 Expression of MMP-7 in UC patients $(\mathbf{n}=\mathbf{4 9}$ ). mRNA results were determined by RT-PCR. MMP-7 gene expression was not significantly different in UC patients with intestinal MAP detection and those without $(p=0.318)$ and did not differ between patients receiving an anti-inflammatory therapy (AIT) and those without AIT $(p=0.094)$. Further stratification into subgroups of patients receiving 5 -amino salicylic acid (5-ASA) and its derivatives, corticosteroids or immunomodulators (azathioprine and infliximab) revealed no significant differences in MMP-7 expression between patients treated with the respective substance and those not receiving the respective agent. Note, that some patients received more than one substance class and therefore appear in more than one subgroup. 

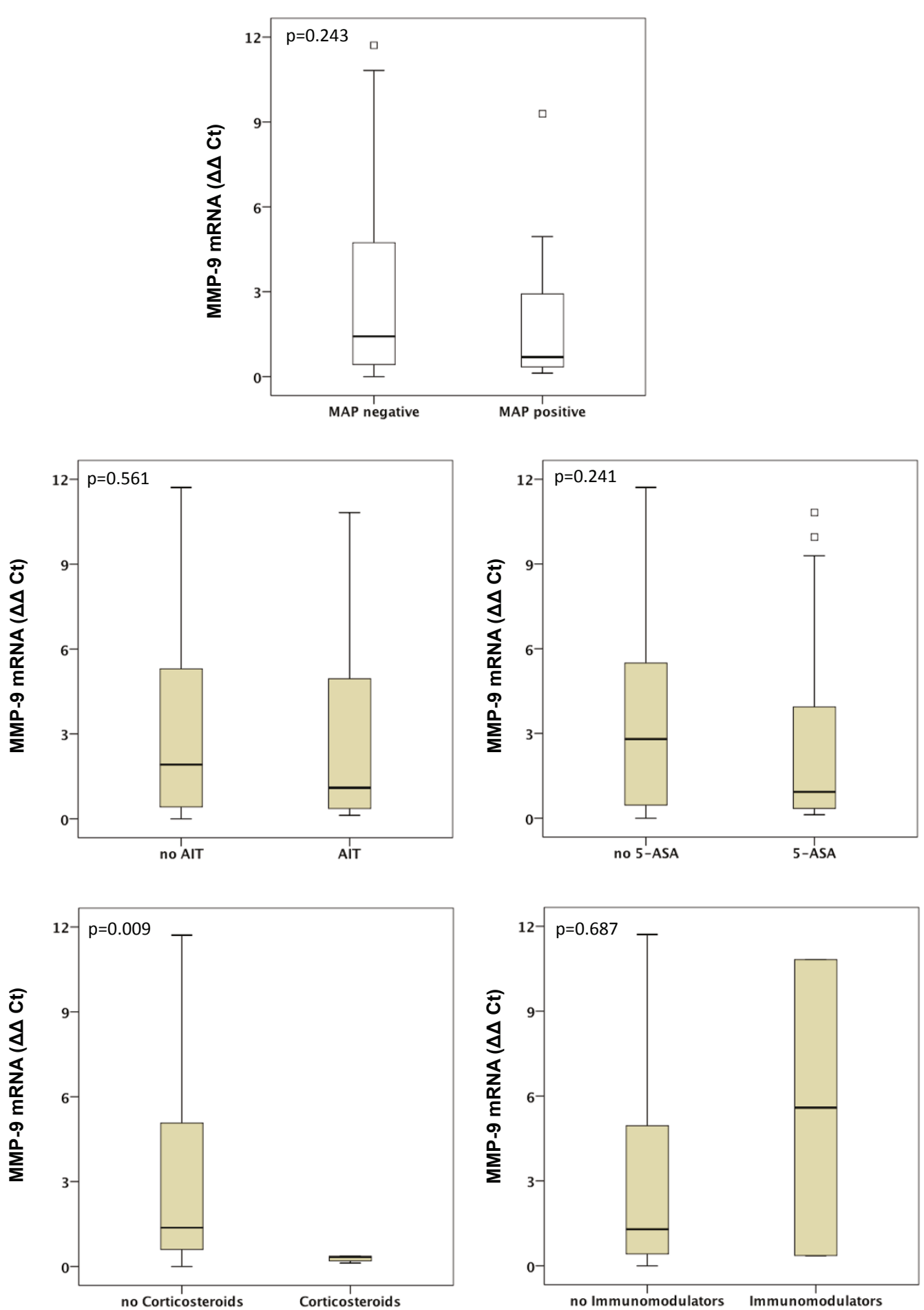

Figure 6 Expression of MMP-9 in UC patients $(\mathbf{n}=\mathbf{4 9})$. mRNA results were determined by RT-PCR. MMP-9 gene expression was not significantly different in UC patients with intestinal MAP detection and those without $(p=0.243$ ) and did not differ between patients receiving an anti-inflammatory therapy (AIT) and those without AIT ( $p=0.561$ ). Further stratification of the UC cohort according to the different therapeutic agents revealed that MMP-9 mRNA is significantly decreased by factor 4.2 in UC patients treated with corticosteroids compared to those with no corticosteroids in their therapeutic regime $(p=0.009)$. No differences in MMP-9 expression were observed when patients receiving 5 -amino salicylic acid (5-ASA) and its derivatives or immunomodulators (azathioprine and infliximab) were compared to patients not treated with the respective agent. Note, that some patients received more than one substance class and therefore appear in more than one subgroup. 

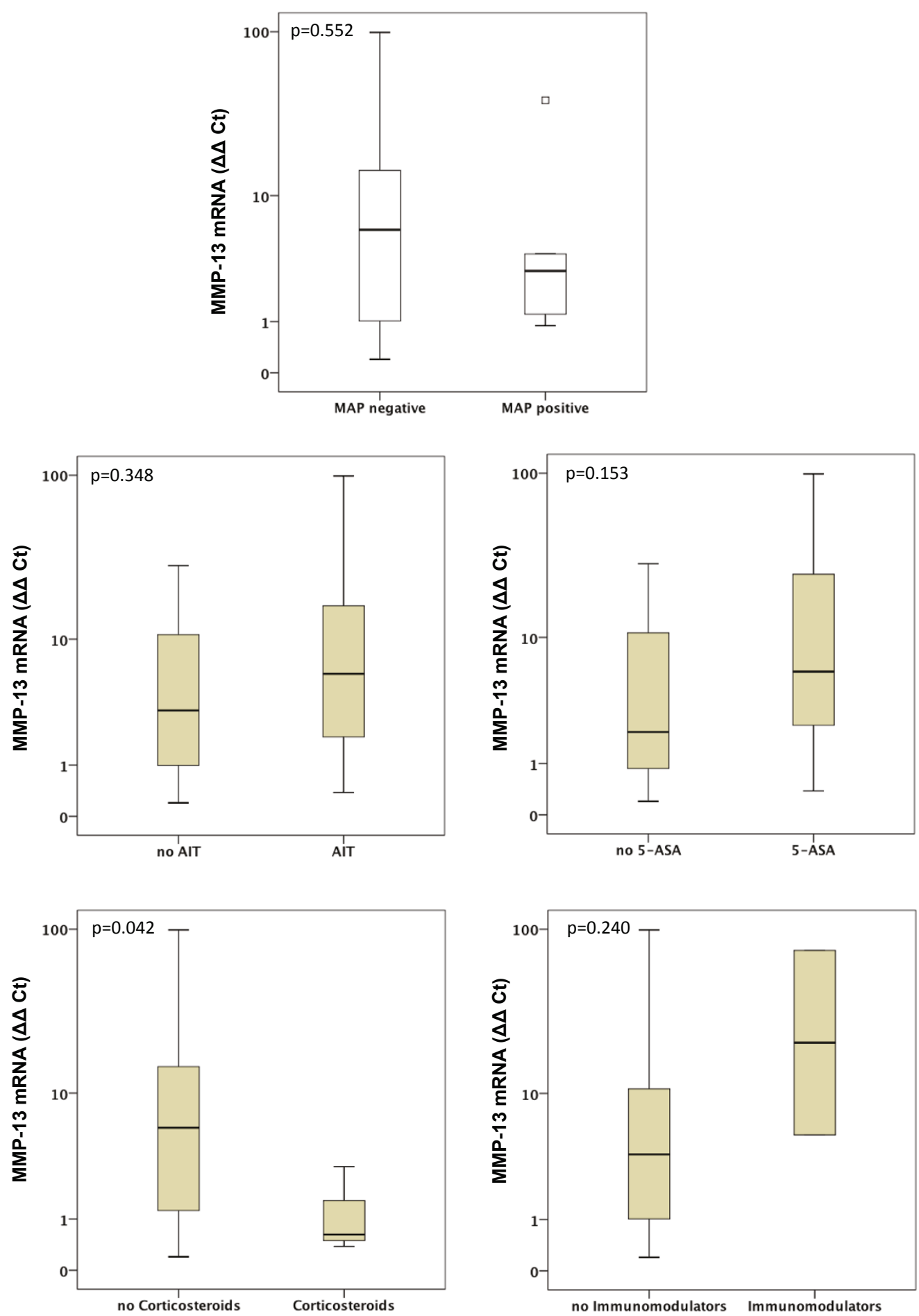

Figure 7 Expression of MMP-13 in UC patients $(\mathbf{n}=\mathbf{4 9})$. mRNA results were determined by RT-PCR. MMP-13 gene expression was not significantly different in UC patients with intestinal MAP detection and those without $(p=0.552)$ and did not differ between patients receiving an anti-inflammatory therapy (AIT) and those without AIT ( $p=0.348$ ). Further stratification of the UC cohort according to the different therapeutic agents revealed that MMP-13 mRNA is significantly decreased by factor 9.5 in UC patients treated with corticosteroids compared to those with no corticosteroids in their therapeutic regime $(p=0.042)$. No differences in MMP-13 expression were observed when patients receiving 5 -amino salicylic acid (5-ASA) and its derivatives or immunomodulators (azathioprine and infliximab) were compared to patients not treated with the respective agent. Note, that some patients received more than one substance class and therefore appear in more than one subgroup. 

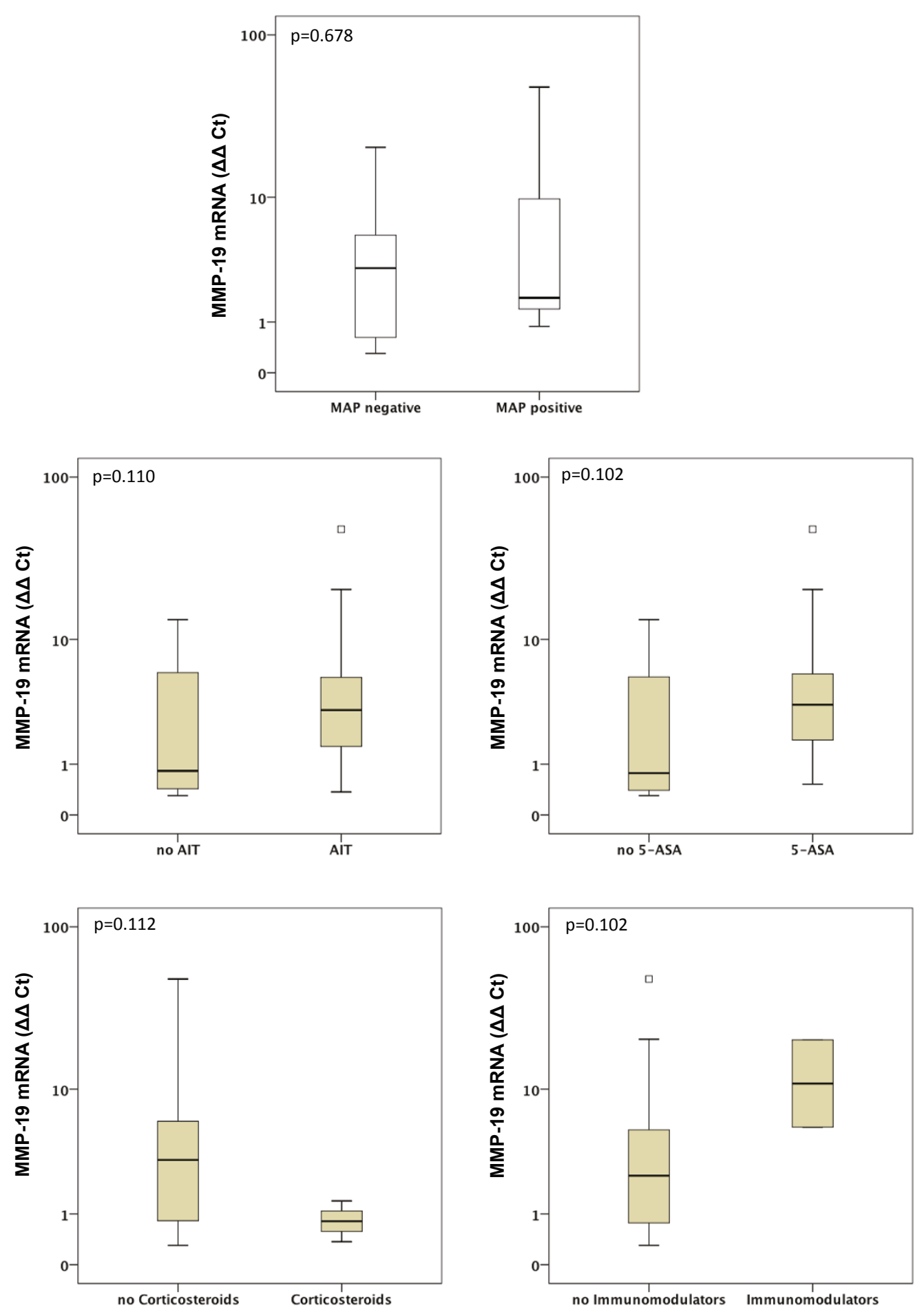

Figure 8 Expression of MMP-19 in UC patients $(\mathbf{n}=\mathbf{4 9})$. mRNA results were determined by RT-PCR. MMP-19 gene expression was not significantly different in UC patients with intestinal MAP detection and those without $(p=0.678)$ and did not differ between patients receiving an anti-inflammatory therapy (AIT) and those without AIT $(p=0.110)$. Further stratification into subgroups of patients receiving 5 -amino salicylic acid (5-ASA) and its derivatives, corticosteroids or immunomodulators (azathioprine and infliximab) revealed no significant differences in MMP-19 expression between patients treated with the respective substance and those not receiving the respective agent. Note, that some patients received more than one substance class and therefore appear in more than one subgroup. 

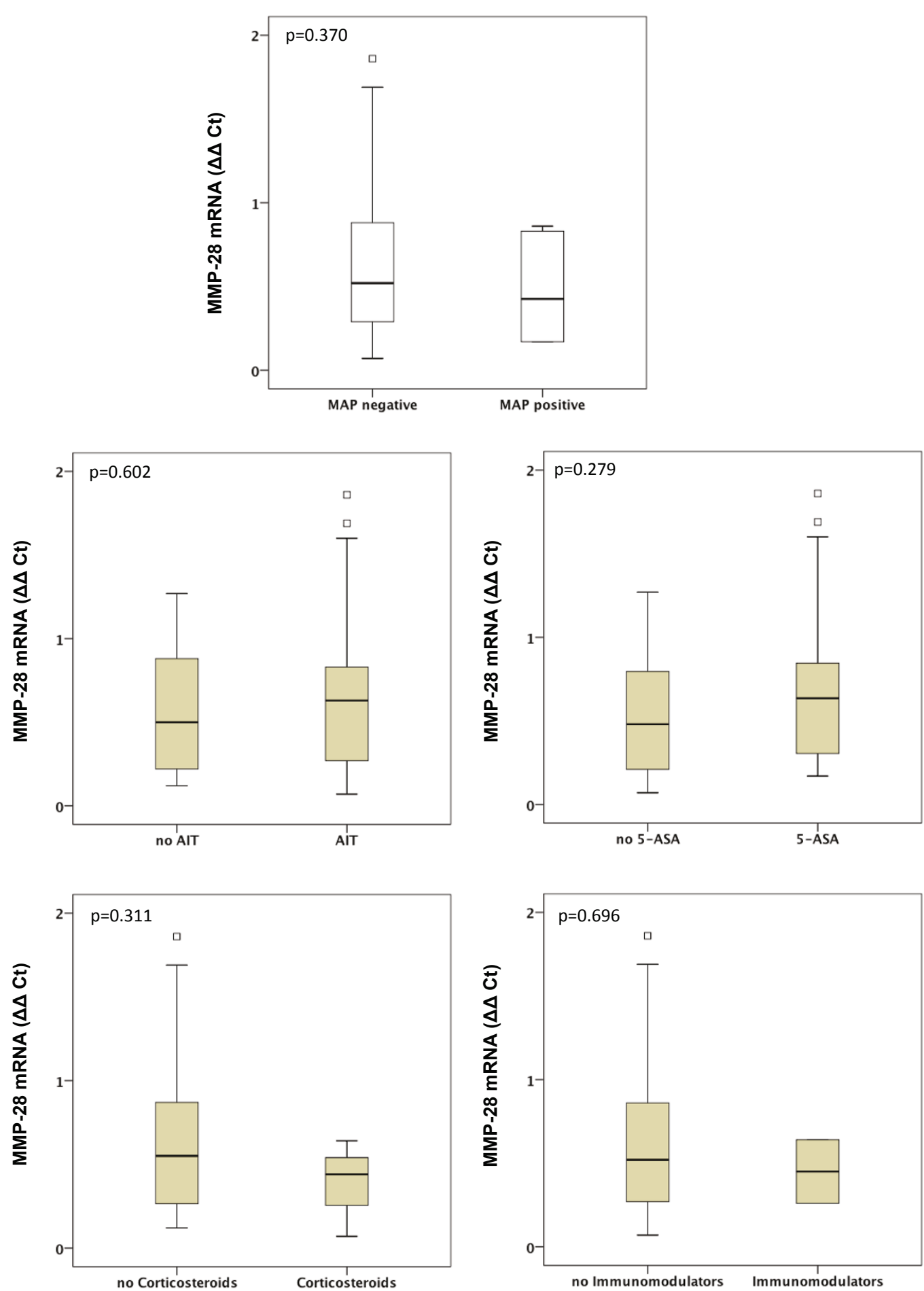

Figure 9 Expression of MMP-28 in UC patients $(\mathbf{n}=\mathbf{4 9})$. mRNA results were determined by RT-PCR. MMP-28 gene expression was not significantly different in UC patients with intestinal MAP detection and those without $(p=0.370)$ and did not differ between patients receiving an anti-inflammatory therapy (AIT) and those without AIT $(p=0.602)$. Further stratification into subgroups of patients receiving 5 -amino salicylic acid (5-ASA) and its derivatives, corticosteroids or immunomodulators (azathioprine and infliximab) revealed no significant differences in MMP-28 expression between patients treated with the respective substance and those not receiving the respective agent. Note, that some patients received more than one substance class and therefore appear in more than one subgroup. 

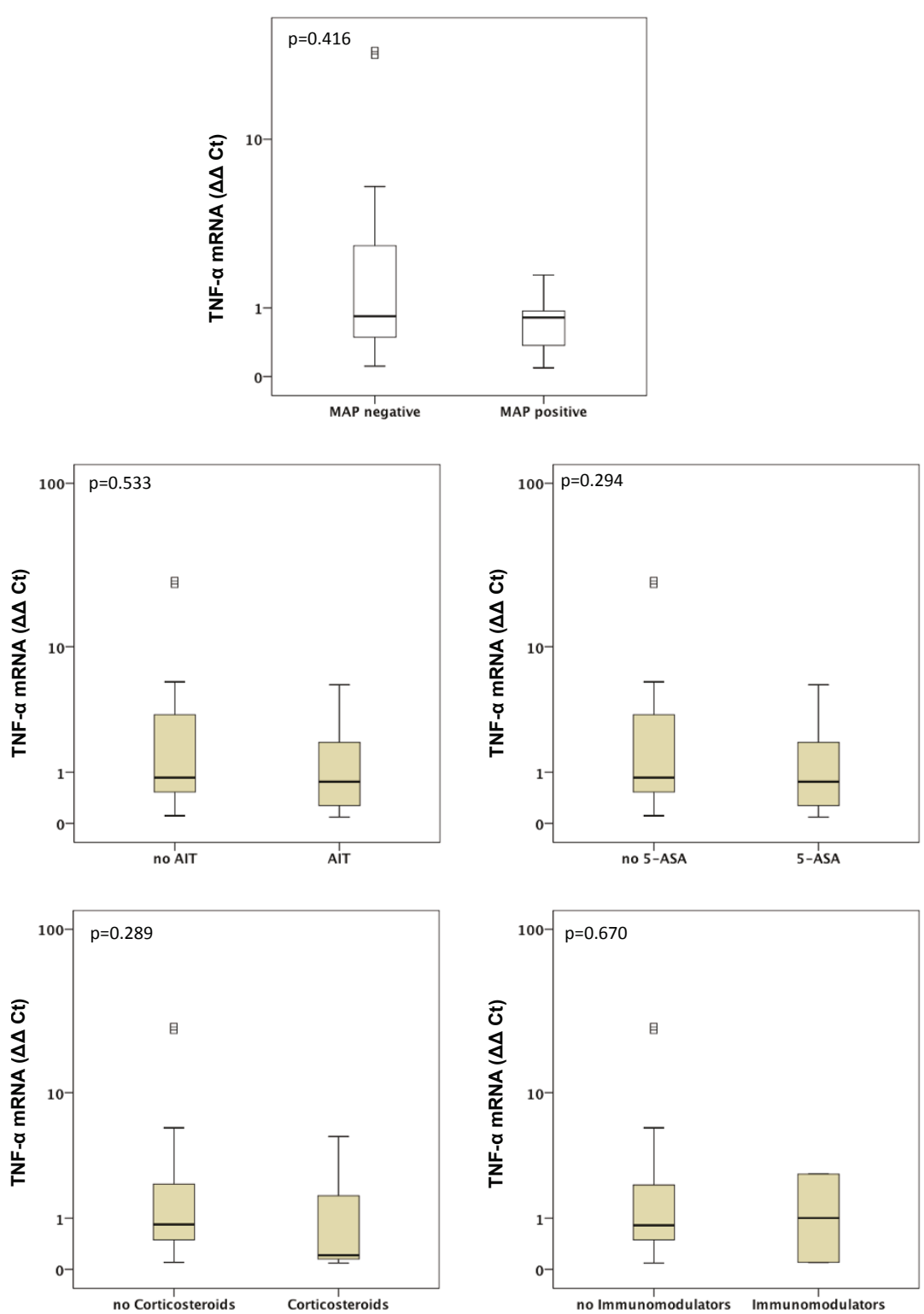

Figure 10 Expression of TNF- $\alpha$ in UC patients $(\mathbf{n}=\mathbf{4 9})$. mRNA results were determined by RT-PCR. TNF- $\alpha$ gene expression was not significantly different in UC patients with intestinal MAP detection and those without $(p=0.416)$ and did not differ between patients receiving an anti-inflammatory therapy (AIT) and those without AIT ( $p=0.533$ ). Further stratification into subgroups of patients receiving 5 -amino salicylic acid (5-ASA) and its derivatives, corticosteroids or immunomodulators (azathioprine and infliximab) revealed no significant differences in TNF- $\alpha$ expression between patients treated with the respective substance and those not receiving the respective agent. Note, that some patients received more than one substance class and therefore appear in more than one subgroup.

\section{Discussion}

The histopathological and clinical similarities between human chronic granulomatous enteritis, intestinal tuberculosis, and animal paratuberculosis $[3,23]$ has led to the suspicion that Mycobacterium avium subspecies paratuberculosis is an etiologic factor for the development of Crohn's disease. MAP is fastidious and slowgrowing and can therefore only rarely be detected by conventional microbiological techniques [1]. Due to the difficulties in growing MAP in vitro, molecular and serological methods have been developed. Nevertheless, the molecular detection of MAP DNA has also frequently been hampered by insufficient specificity of the selected primers and probes, inadequate DNA extraction methods resulting in insufficient sensitivity, and possible contamination as a consequence of the PCR techniques used [24]. In the current study, we therefore selected a nested PCR system and a real time-PCR method instead 
of conventional PCR sets, which ensured a sensitive and specific approach. The nested PCR used was developed by Bull et al. [21] and is based on the widely used MAP reference marker IS900. The oligonucleotide primer sequences were specifically adapted to show no cross reactions with the previously described IS900-like elements $[25,26]$. The positive IS900 PCR products detected were sequenced and corresponded to MAP IS900 but not IS900-like sequences. In addition, a triplex real-time PCR assay combining the MAP-specific gene sequences F57, ISMav2, and an internal amplification control for diagnostic quality assurance was applied. The real time-PCR method was carefully validated by using more than 200 references and field strains with different kinds of sample preparation techniques on artificially contaminated and naturally infected samples.

Based on 2 different PCR methods utilized in this study, false-positive results due to an unspecific binding of oligonucleotide primer pairs are therefore highly improbable. The risk of cross-contamination between the samples was also reduced by using sample preparation negative controls. The use of an IAC has been shown to be mandatory for diagnostic PCR applications to exclude false negative results [27]. The included IAC of the real-time PCR assay revealed that none of the real-time PCR reactions was inhibited.

Using this specific and sensitive approach, we explored the detection rate of MAP DNA in colonic biopsies of German and Norwegian patients with IBD and control patients without intestinal inflammation. Within this study, we found no significant differences in MAP DNA detection frequency between patients with $\mathrm{UC}$ and $\mathrm{CD}$ and controls.

Regarding the literature, reports about the association of MAP and CD are controversial. So far, a number of studies have reported more frequent detection of MAP DNA in CD patients compared with controls using PCR assays $[21,28,29]$. Other authors, in contrast, found no association between $\mathrm{CD}$ and the detection of MAP DNA [30-35]. Nevertheless, comparisons between the studies are difficult to make due to heterogeneity in the analysed specimens that vary from fresh $[35,36]$ to embedded tissue [30,31] and blood [28,29,32-34]. Furthermore, different MAP detection methods are used across the studies including MAP DNA [21,28,30,31,33-35], MAP culture [29,32,34], both DNA and culture [34], specific antibodies against MAP epitopes [28] and immunocytochemistry [31]. Although recent meta-analyses were able to confirm the association of MAP infection and CD [4,6], the pathogenic significance of this association remains unclear. Within our study, we detected MAP DNA in only a low percentage of CD patients. As a limiting factor, our cohort of patients with $C D$ was relatively small. Post hoc power analysis of the CD population against an alpha level of 0.05 estimated a two-tailed statistical power of 0.135 . Consequently, appropriate conclusions about an etiologic involvement of MAP in the pathogenesis of $C D$ cannot be drawn from the results of our study.

During the initial phase of our study, we detected MAP DNA in an unexpected high percentage of German UC patients. To exclude a locoregional influence or epiphenomenon, we aimed to confirm this result in a distinct UC population and therefore expanded our analyses to a cohort of Norwegian UC patients. In this cohort, we likewise observed a high frequency of MAP DNA. Data on the frequency of MAP detection in UC in the literature are contradictory as well. In general, MAP is more frequently detected in $\mathrm{CD}$ than in $\mathrm{UC}$ according to recent meta-analyses $[4,6]$. Nevertheless, several studies detected MAP infection in a high percentage of UC patients as well [7,28,37-40].

As a further remarkable result, we detected MAP DNA in intact colonic mucosa in a high percentage of German control patients (33\%). As both, the Norwegian and German patient population represent an urban population with a comparable demographic and epidemiologic structure and a similar BCG vaccination policy in Germany and Norway, we did not assess the colonic MAP prevalence in healthy Norwegians. In conjunction with our results, previous studies have made similar observations by serologically detecting MAP DNA or specific MAP antibodies in a high percentage of healthy control patients [37,39-41]. In this context, the following aspects are important to note: MAP has been cultured from chlorinated potable municipal water [42]. Mycobacteria are at least two orders of magnitude more resistant to chlorine purification than Escherichia coli and MAP survives higher concentrations of chlorine than the 1.1 parts per million routinely achieved with firstuse municipal water in the USA [43]. Furthermore, MAP has been cultured from pasteurized milk in the USA and Europe [44-46]. Considering these facts, it has been speculated that the frequent detection of MAP in healthy controls is a result of the wide distribution of MAP and its presence in the food-chain. Nevertheless, the biological significance of this finding remains unclear as the detection of MAP DNA might well come from live bacteria but also might merely represent scattered debris from killed bacteria.

Anti-inflammatory agents such as 5-ASA and its derivatives, corticosteroids and immunomodulators are established therapeutic agents for the treatment of IBD. Most interestingly, it has been shown that 5-ASA, thalidomide, methotrexate, 6-mercaptopurine and azathioprine inhibit MAP in vitro in a dose dependent manner [47-50]. Further, recent evidence suggests that 5-ASA 
decreases the prevalence of MAP DNA from the blood of IBD patients whereas other agents such as 6-mercaptopurin, methotrexate and tacrolimus are associated with clearance of MAP DNA from the blood [39]. To analyse a potential effect of the applied anti-inflammatory therapy on the MAP DNA prevalence in intestinal tissue, we performed subgroup analyses according to the different therapeutic agents in our IBD cohort. However, we were not able to detect significant differences in the MAP DNA prevalence between IBD and UC patients with and without anti-inflammatory therapy and between those patients receiving 5-ASA or immunomodulators compared to patients without the respective agents. Based on the unrefuted data of the anti-MAP activities of IBD medication mentioned above, we assume that the most likely explanation for the lack of association between 5-ASA and immunomodulators and MAP detection rates within our study, apart from the different specimens analysed (tissue vs. blood), is the relative small sample size in our study. Nevertheless, our results provide evidence that UC patients treated with corticosteroids have a higher frequency of intestinal MAP DNA than those not treated with corticosteroids. This result is in accordance with observations from Naser et al. who cultured MAP from blood in 60\% (3 of 5) of IBD patients treated with steroids [29]. Although a larger study by Juste and co-workers did not detect a significant increase in MAP prevalence in patients receiving steroids, the authors suggested that the lack of increased MAP DNA frequency in steroid treated IBD patients in their study might be attributable to frequent co-administration of anti-MAP agents in this group [39]. Furthermore, the authors concluded that caution suggests that concomitant anti-MAP agents should always be used when steroids are administered [39], a position that is strengthened by the results of our study.

To further evaluate a potential contribution of MAP infection to disease manifestation in UC patients, we analysed the expression of Matrix Metalloproteinases with regard to the presence or absence of intestinal MAP DNA. Members of the MMP family have been shown to be upregulated in peripheral blood mononuclear cells from cattle infected with Johne's disease after stimulation with MAP $[16,17]$. Furthermore, murine in vitro and in vivo studies provide evidence that upregulation of certain MMPs such as MMP-2 and MMP-9 plays a pathogenic role in infections caused by pathogenic mycobacteria [18]. Most interestingly, enhanced MMP activity after mycobacterial infection was substantially reduced upon treatment with anti-TNF $\alpha$ antibodies [18], a treatment strategy which has been proven to be highly beneficial in human IBD $[51,52]$. On the other hand, in vitro data from Janagama and co-workers demonstrate that MAP strains from diverse hosts differ in their ability to survive intracellularly and that strains with higher intracellular persistence had decreased expression of different cytokines and MMP-3 [53]. Thus, an anti-inflammatory and anti-invasive milieu might facilitate their persistence and survival within macrophages [53].

On the basis of this evidence, we aimed to analyse the mucosal MMP expression in IBD patients with and without intestinal MAP DNA. Unfortunately, we had to restrict the analysis to the UC patient cohort, as MAP DNA was detected in only one CD patient. Using this approach we focused on MMP gene expression as several studies have shown that expression of MMPs is mainly transcriptional regulated with close correlation between MMP protein concentrations and mRNA expression [54-57]. We analysed a broad spectrum of MMPs including MMP-1, MMP-7 and MMP-13, which have been proven to be major proteases in the pathogenesis of IBD associated mucosal ulcerations [13-15,58,59], and MMP-2 and MMP-9, which have been shown to be upregulated upon mycobacterial infection [18]. Furthermore, we determined the expression of MMP-28, the most recent member of the MMP family which is expressed in intact colonic epithelium rather than in UC affected mucosa and therefore is associated with epithelial integrity $[14,60]$. Our results provide evidence that neither expression of MMP$1,-2,-7,-9,-13,-19$ nor of MMP-28 is altered in UC patients with presence of intestinal MAP DNA compared to those without MAP detection. TNF- $\alpha$, which regulates MMP-2 and MMP-9 and is part of the cytokine response towards MAP in $\mathrm{CD}$ patients $[10,11,61,62]$, was unchanged between UC patients with intestinal MAP DNA detection and those without. Subgroup analyses based on different anti-inflammatory agents applied in our IBD cohort revealed significantly decreased MMP-2, MMP-9, and MMP-13 gene transcripts in UC patients treated with corticosteroids compared to those with no corticosteroids in their therapeutic regime (MMP-2: 6.1-fold, $\mathrm{p}=$ 0.024; MMP-9: 4.2-fold, $\mathrm{p}=0.009$; MMP-13: 9.5 -fold, $\mathrm{p}=0.042$ ). However, when we excluded steroidtreated patients in a further analysis and re-calculated the MMP and TNF- $\alpha$ expression in MAP positive and MAP negative IBD patients, no significant differences were observed between MAP positive and MAP negative patients (Additional Files 1, 2, 3, 4).

To further elucidate the pathogenic potential of MAP for the development of IBD and its significance in healthy individuals, it seems inevitable to transfer the results of the observed association of MAP and IBD to more functional studies in the future. To understand different susceptibilities towards MAP infections, it will be of great value to determine the presence or absence of certain 
genetic IBD risk loci in $\mathrm{CD}$ and UC patients. Among others, NOD2 and Nramp1 might be of particular interest in the context of MAP infection: approximately $30 \%$ of European ancestry have one of three NOD2 polymorphisms and homozygosity for one polymorphism confers an increased risk for CD by factor 11 to 27 [2]. Interestingly, embryonic kidney cells transfected with NOD2 are able to recognize MAP and respond in a dose dependent manner [63]. Defects and mutations in Nrmap (natural-resistance-associated macrophage protein 1) are associated with increased susceptibility to mycobacterial infections in humans and animals and in both, UC and CD patients have a frequency of Nramp1 promoter polymorphisms than healthy controls [64]. Another potential approach might be the use murine models with knockdown of certain IBD susceptibility loci and subsequent controlled infection with MAP strains and other mycobacteria.

\section{Conclusions}

Our study provides evidence that MAP can frequently be detected in intestinal mucosa of patients suffering from ulcerative colitis as well as from control patients without intestinal inflammation. This result might well be attributable to the wide environmental distribution of MAP and its presence in the food-chain. Furthermore, we are able to show that corticosteroids are associated with increased detection of intestinal MAP DNA and decreased expression of certain MMPs. The results of this study provide further evidence that the presence of intestinal MAP specific DNA is not associated with altered MMP expression in ulcerative colitis in vivo. Hence, the biological significance of MAP and its contribution to the pathogenesis of IBD remains elusive.

\section{Additional material}

Additional file 1: Expression of MMP-1 and MMP-2 in UC patients without corticosteroids with respect to the presence of MAP DNA $(\mathbf{n}=\mathbf{4 1})$. mRNA results were determined by RT-PCR. MMP-1 and MMP-2 gene expression was not significantly different in steroidfree UC patients with intestinal MAP detection compared to those without.

Additional file 2: Expression of MMP-7 and MMP-9 in UC patients without corticosteroids with respect to the presence of MAP DNA $(\mathbf{n}=\mathbf{4 1})$. mRNA results were determined by RT-PCR. MMP-7 and MMP-9 gene expression was not significantly different in steroidfree UC patients with intestinal MAP detection compared to those without.

Additional file 3: Expression of MMP-13 and MMP-19 in UC patients without corticosteroids with respect to the presence of MAP DNA $(n=41)$. mRNA results were determined by RT-PCR. MMP-13 and MMP19 gene expression was not significantly different in steroidfree UC patients with intestinal MAP detection compared to those without.

Additional file 4: Expression of MMP-28 and TNF- $\alpha$ in UC patients without corticosteroids with respect to the presence of MAP DNA $(\mathbf{n}=\mathbf{4 1})$. mRNA results were determined by RT-PCR. MMP- 28 and TNF- $\alpha$ gene expression was not significantly different in steroidfree UC patients with intestinal MAP detection compared to those without.

\section{Acknowledgements}

This work was supported by grants from ZooMAP (Bundesministerium für Bildung und Forschung, BMBF) and from the Deutsche Forschungsgemeinschaft (RO 957/7-1 and RO 957/8-1). Dr. Timo Rath has received grants for young researchers ("Anschubfinanzierung") from the Justus-Liebig-University Giessen.

\section{Author details}

'Department of Gastroenterology, Medical Clinic II, Justus Liebig University, Paul-Meimberg-Strasse 5, 35392 Giessen, Germany. ${ }^{2}$ Institute for Microbiology, Centre for Infectious Medicine, Veterinarian Medical Academy Hannover, Bischofsholer Damm 15, 30173 Hannover, Germany. ${ }^{3}$ Institute of Veterinary Food Science, Faculty of Veterinary Medicine, Justus Liebig University, Frankfurter Strasse 92, 35392 Giessen, Germany. ${ }^{4}$ Department of Internal Medicine, University Hospital Stavanger, 4011 Stavanger, Norway. ${ }^{5}$ Department of Internal Medicine, Stord Hospital, 5416 Stord, Norway.

\section{Authors' contributions}

TR participated in the collection the biopsy samples, determined the MMP expression, analysed the data and drafted the manuscript (together with ER). $M R, S B$ and AR participated in study design, collection of the biopsy samples and MMP analyses. OA, AA and MB performed the MAP detection and critically revised the manuscript. JMH participated in the collection of the biopsy samples and MMP analyses. TB and RG provided important intellectual content and participated in study design. ER designed the study, analysed the data and drafted the manuscript (together with TR). All authors read and approved the final manuscript.

\section{Competing interests}

TR has no competing interests to disclose. MR has no competing interests to disclose. SB has no competing interests to disclose. AR has no competing interests to disclose. TB has no competing interests to disclose. ÖA has no competing interests to disclose. AA has no competing interests to disclose. $\mathrm{JMH}$ has no competing interests to disclose. RG has no competing interests to disclose. MB has no competing interests to disclose. ER has no competing interests to disclose.

Received: 26 October 2010 Accepted: 8 April 2011 Published: 8 April 2011

\section{References}

1. Tiwari A, VanLeeuwen JA, McKenna SL, Keefe GP, Barkema HW: Johne's disease in Canada Part I: clinical symptoms, pathophysiology, diagnosis, and prevalence in dairy herds. Can Vet J 2006, 47:874-882

2. Abraham C, Cho JH: Inflammatory bowel disease. N Engl J Med 2009, 361:2066-2078.

3. Dalziel TK: Chronical intestinal enteritis. Br Med J 1913, 2:1068-1070.

4. Abubakar I, Myhill D, Aliyu SH, Hunter PR: Detection of Mycobacterium avium subspecies paratuberculosis from patients with Crohn's disease using nucleic acid-based techniques: a systematic review and metaanalysis. Inflamm Bowel Dis 2008, 14:401-410.

5. Behr MA, Kapur $\mathrm{V}$ : The evidence for Mycobacterium paratuberculosis in Crohn's disease. Curr Opin Gastroenterol 2008, 24:17-21.

6. Feller M, Huwiler K, Stephan R, Altpeter E, Shang A, Furrer H, Pfyffer GE, Jemmi T, Baumgartner A, Egger M: Mycobacterium avium subspecies paratuberculosis and Crohn's disease: a systematic review and metaanalysis. Lancet Infect Dis 2007, 7:607-613.

7. Kirkwood CD, Wagner J, Boniface K, Vaughan J, Michalski WP, CattoSmith AG, Cameron DJ, Bishop RF: Mycobacterium avium subspecies paratuberculosis in children with early-onset Crohn's disease. Inflamm Bowel Dis 2009, 15:1643-1655.

8. Chamberlin WM, Naser SA: Integrating theories of the etiology of Crohn's disease. On the etiology of Crohn's disease: questioning the hypotheses. Med Sci Monit 2006, 12:RA27-33.

9. Mendoza JL, Lana R, Diaz-Rubio M: Mycobacterium avium subspecies paratuberculosis and its relationship with Crohn's disease. World J Gastroenterol 2009, 15:417-422.

10. Clancy R, Ren Z, Turton J, Pang G, Wettstein A: Molecular evidence for Mycobacterium avium subspecies paratuberculosis (MAP) in Crohn's disease correlates with enhanced TNF-alpha secretion. Dig Liver Dis 2007, 39:445-451. 
11. Sibartie S, Scully P, Keohane J, O'Neill S, O'Mahony J, O'Hanlon D, Kirwan WO, O'Mahony L, Shanahan F: Mycobacterium avium subsp. Paratuberculosis (MAP) as a modifying factor in Crohn's disease. Inflamm Bowel Dis 2010, 16:296-304.

12. Parks WC, Wilson CL, Lopez-Boado YS: Matrix metalloproteinases as modulators of inflammation and innate immunity. Nat Rev Immunol 2004, 4:617-629.

13. Rath T, Roderfeld M, Graf J, Roeb E: [Matrix metalloproteinases in inflammatory bowel disease - from basic research to clinical significance]. Z Gastroenterol 2009, 47:758-769.

14. Rath T, Roderfeld M, Halwe JM, Tschuschner A, Roeb E, Graf J: Cellular sources of MMP-7, MMP-13 and MMP-28 in ulcerative colitis. Scand J Gastroenterol 2010, 45:1186-1196.

15. Ravi A, Garg P, Sitaraman SV: Matrix metalloproteinases in inflammatory bowel disease: boon or a bane? Inflamm Bowel Dis 2007, 13:97-107.

16. Coussens PM, Colvin CJ, Rosa GJ, Perez Laspiur J, Elftman MD: Evidence for a novel gene expression program in peripheral blood mononuclear cells from Mycobacterium avium subsp. paratuberculosis-infected cattle. Infect Immun 2003, 71:6487-6498.

17. Coussens PM, Pudrith CB, Skovgaard K, Ren X, Suchyta SP, Stabel JR, Heegaard PM: Johne's disease in cattle is associated with enhanced expression of genes encoding IL-5, GATA-3, tissue inhibitors of matrix metalloproteinases 1 and 2, and factors promoting apoptosis in peripheral blood mononuclear cells. Vet Immunol Immunopathol 2005, 105:221-234.

18. Quiding-Jarbrink M, Smith DA, Bancroft GJ: Production of matrix metalloproteinases in response to mycobacterial infection. Infect Immun 2001, 69:5661-5670.

19. Schroeder KW, Tremaine WJ, Ilstrup DM: Coated oral 5-aminosalicylic acid therapy for mildly to moderately active ulcerative colitis. A randomized study. N Engl J Med 1987, 317:1625-1629.

20. Schonenbrucher $H$, Abdulmawjood A, Failing K, Bulte M: New triplex realtime PCR assay for detection of Mycobacterium avium subsp. paratuberculosis in bovine feces. Appl Environ Microbiol 2008, 74:2751-2758.

21. Bull TJ, McMinn EJ, Sidi-Boumedine K, Skull A, Durkin D, Neild P, Rhodes G, Pickup R, Hermon-Taylor J: Detection and verification of Mycobacterium avium subsp. paratuberculosis in fresh ileocolonic mucosal biopsy specimens from individuals with and without Crohn's disease. J Clin Microbiol 2003, 41:2915-2923.

22. Pfaffl MW: A new mathematical model for relative quantification in realtime RT-PCR. Nucleic Acids Res 2001, 29:e45.

23. Chacon O, Bermudez LE, Barletta RG: Johne's disease, inflammatory bowel disease, and Mycobacterium paratuberculosis. Annu Rev Microbiol 2004, 58:329-363.

24. Harris NB, Barletta RG: Mycobacterium avium subsp. paratuberculosis in Veterinary Medicine. Clin Microbiol Rev 2001, 14:489-512.

25. Cousins DV, Whittington R, Marsh I, Masters A, Evans RJ, Kluver P: Mycobacteria distenct from Mycobacterium avium subsp. paratuberculosis isolated from the faeces of ruminants possess IS900 like sequences detectable IS900 polymerase chain reaction: implications for diagnosis. Mol Cell Probes 1999, 13:431-442.

26. Englund S, Bolske G, Johansson KE: An IS900-like sequence found in a Mycobacterium sp. other than Mycobacterium avium subsp. paratuberculosis. FEMS Microbiol Lett 2002, 209:267-271.

27. Hoorfar J, Cook N, Malorny B, Wagner M, De Medici D, Abdulmawjood A, Fach P: Diagnostic PCR: making internal amplification control mandatory. Lett Appl Microbiol 2004, 38:79-80.

28. Di Sabatino A, Paccagnini D, Vidali F, Rosu V, Biancheri P, Cossu A, Zanetti S, Corazza GR, Sechi LA: Detection of Mycobacterium avium subsp. paratuberculosis (MAP)-specific IS900 DNA and antibodies against MAP peptides and lysate in the blood of Crohn's disease patients. Inflamm Bowel Dis 2010.

29. Naser SA, Ghobrial G, Romero C, Valentine JF: Culture of Mycobacterium avium subspecies paratuberculosis from the blood of patients with Crohn's disease. Lancet 2004, 364:1039-1044.

30. Baksh FK, Finkelstein SD, Ariyanayagam-Baksh SM, Swalsky PA, Klein EC, Dunn JC: Absence of Mycobacterium avium subsp. paratuberculosis in the microdissected granulomas of Crohn's disease. Mod Pathol 2004, 17:1289-1294.

31. Ellingson JL, Cheville JC, Brees D, Miller JM, Cheville NF: Absence of Mycobacterium avium subspecies paratuberculosis components from Crohn's disease intestinal biopsy tissues. Clin Med Res 2003, 1:217-226.
32. Freeman $\mathrm{H}$, Noble M: Lack of evidence for Mycobacterium avium subspecies paratuberculosis in Crohn's disease. Inflamm Bowel Dis 2005, 11:782-783.

33. Lozano-Leon A, Barreiro-de Acosta M, Dominguez-Munoz JE: Absence of Mycobacterium avium subspecies paratuberculosis in Crohn's disease patients. Inflamm Bowel Dis 2006, 12:1190-1192.

34. Parrish NM, Radcliff RP, Brey BJ, Anderson JL, Clark DL, Koziczkowski J J, Ko CG, Goldberg ND, Brinker DA, Carlson RA, et al: Absence of mycobacterium avium subsp. paratuberculosis in Crohn's patients. Inflamm Bowel Dis 2009, 15:558-565.

35. Sasikala M, Reddy DN, Pratap N, Sharma SK, Balkumar PR, Sekaran A, Banerjee R, Reddy DB: Absence of Mycobacterium avium ss paratuberculosis-specific IS900 sequence in intestinal biopsy tissues of Indian patients with Crohn's disease. Indian J Gastroenterol 2009, 28:169-174.

36. Bull TJ, Hermon-Taylor J, Pavlik I, El-Zaatari F, Tizard M: Characterization of IS900 loci in Mycobacterium avium subsp. paratuberculosis and development of multiplex PCR typing. Microbiology 2000, 146(Pt 9):2185-2197.

37. Bernstein CN, Blanchard JF, Rawsthorne P, Collins MT: Population-based case control study of seroprevalence of Mycobacterium paratuberculosis in patients with Crohn's disease and ulcerative colitis. J Clin Microbiol 2004, 42:1129-1135.

38. Collins MT, Lisby G, Moser C, Chicks D, Christensen S, Reichelderfer M, Hoiby N, Harms BA, Thomsen OO, Skibsted U, Binder V: Results of multiple diagnostic tests for Mycobacterium avium subsp. paratuberculosis in patients with inflammatory bowel disease and in controls. J Clin Microbiol 2000, 38:4373-4381.

39. Juste RA, Elguezabal N, Garrido JM, Pavon A, Geijo MV, Sevilla I, Cabriada JL, Tejada A, Garcia-Campos F, Casado R, et al: On the prevalence of M. avium subspecies paratuberculosis DNA in the blood of healthy individuals and patients with inflammatory bowel disease. PLOS One 2008, 3:e2537.

40. Mendoza JL, San-Pedro A, Culebras E, Cies R, Taxonera C, Lana R, Urcelay E, de la Torre F, Picazo JJ, Diaz-Rubio M: High prevalence of viable Mycobacterium avium subspecies paratuberculosis in Crohn's disease. World J Gastroenterol 2010, 16:4558-4563.

41. Juste RA, Elguezabal N, Pavon A, Garrido JM, Geijo M, Sevilla I, Cabriada JL, Tejada A, Garcia-Campos F, Casado R, et al: Association between Mycobacterium avium subsp. paratuberculosis DNA in blood and cellular and humoral immune response in inflammatory bowel disease patients and controls. Int J Infect Dis 2009, 13:247-254.

42. Mishina D, Katsel P, Brown ST, Gilberts EC, Greenstein RJ: On the etiology of Crohn disease. Proc Natl Acad Sci USA 1996, 93:9816-9820.

43. Whan LB, Grant IR, Ball HJ, Scott R, Rowe MT: Bactericidal effect of chlorine on Mycobacterium paratuberculosis in drinking water. Lett Appl Microbiol 2001, 33:227-231.

44. Ayele WY, Svastova P, Roubal P, Bartos M, Pavlik I: Mycobacterium avium subspecies paratuberculosis cultured from locally and commercially pasteurized cow's milk in the Czech Republic. App/ Environ Microbiol 2005, 71:1210-1214.

45. Ellingson JL, Anderson JL, Koziczkowski JJ, Radcliff RP, Sloan SJ, Allen SE, Sullivan NM: Detection of viable Mycobacterium avium subsp. paratuberculosis in retail pasteurized whole milk by two culture methods and PCR. J Food Prot 2005, 68:966-972.

46. Grant IR, Hitchings El, McCartney A, Ferguson F, Rowe MT: Effect of commercial-scale high-temperature, short-time pasteurization on the viability of Mycobacterium paratuberculosis in naturally infected cows' milk. Appl Environ Microbiol 2002, 68:602-607.

47. Greenstein RJ, Su L, Brown ST: On the effect of thalidomide on Mycobacterium avium subspecies paratuberculosis in culture. Int J Infect Dis 2009, 13:e254-263.

48. Greenstein RJ, Su L, Haroutunian V, Shahidi A, Brown ST: On the action of methotrexate and 6-mercaptopurine on M. avium subspecies paratuberculosis. PLoS One 2007, 2:e161.

49. Greenstein RJ, Su L, Shahidi A, Brown ST: On the action of 5-aminosalicylic acid and sulfapyridine on M. avium including subspecies paratuberculosis. PLoS One 2007, 2:e516.

50. Shin SJ, Collins MT: Thiopurine drugs azathioprine and 6-mercaptopurine inhibit Mycobacterium paratuberculosis growth in vitro. Antimicrob Agents Chemother 2008, 52:418-426. 
51. Rutgeerts P, D'Haens G, Targan S, Vasiliauskas E, Hanauer SB, Present DH, Mayer L, Van Hogezand RA, Braakman T, DeWoody KL, et al: Efficacy and safety of retreatment with anti-tumor necrosis factor antibody (infliximab) to maintain remission in Crohn's disease. Gastroenterology 1999, 117:761-769

52. Rutgeerts P, Sandborn WJ, Feagan BG, Reinisch W, Olson A, Johanns J, Travers S, Rachmilewitz D, Hanauer SB, Lichtenstein GR, et al: Infliximab for induction and maintenance therapy for ulcerative colitis. $N$ Engl I Med 2005, 353:2462-2476.

53. Janagama HK, Jeong K, Kapur V, Coussens P, Sreevatsan S: Cytokine responses of bovine macrophages to diverse clinical Mycobacterium avium subspecies paratuberculosis strains. BMC Microbiol 2006, 6:10.

54. Graham MF, Willey A, Zhu YN, Yager DR, Sugerman HJ, Diegelmann RF: Corticosteroids repress the interleukin 1 beta-induced secretion of collagenase in human intestinal smooth muscle cells. Gastroenterology 1997, 113:1924-1929.

55. Kohn EC, Jacobs W, Kim YS, Alessandro R, Stetler-Stevenson WG, Liotta LA: Calcium influx modulates expression of matrix metalloproteinase-2 (72kDa type IV collagenase, gelatinase A). J Biol Chem 1994, 269:21505-21511.

56. MacNaul KL, Chartrain N, Lark M, Tocci MJ, Hutchinson NI: Discoordinate expression of stromelysin, collagenase, and tissue inhibitor of metalloproteinases-1 in rheumatoid human synovial fibroblasts. Synergistic effects of interleukin-1 and tumor necrosis factor-alpha on stromelysin expression. J Biol Chem 1990, 265:17238-17245.

57. Rath T, Roderfeld M, Graf J, Wagner S, Vehr AK, Dietrich C, Geier A, Roeb E: Enhanced expression of MMP-7 and MMP-13 in inflammatory bowel disease: a precancerous potential? Inflamm Bowel Dis 2006, 12:1025-1035.

58. Arihiro S, Ohtani H, Hiwatashi N, Torii A, Sorsa T, Nagura H: Vascular smooth muscle cells and pericytes express MMP-1, MMP-9, TIMP-1 and type I procollagen in inflammatory bowel disease. Histopathology 2001, 39:50-59.

59. Matsuno $K$, Adachi $Y$, Yamamoto $H$, Goto A, Arimura $Y$, Endo $T$, Itoh $F$, Imai K: The expression of matrix metalloproteinase matrilysin indicates the degree of inflammation in ulcerative colitis. J Gastroenterol 2003, 38:348-354.

60. Bister VO, Salmela MT, Karjalainen-Lindsberg ML, Uria J, Lohi J, Puolakkainen P, Lopez-Otin C, Saarialho-Kere U: Differential expression of three matrix metalloproteinases, MMP-19, MMP-26, and MMP-28, in normal and inflamed intestine and colon cancer. Dig Dis Sci 2004, 49:653-661.

61. Han YP, Tuan TL, Wu H, Hughes M, Garner WL: TNF-alpha stimulates activation of pro-MMP2 in human skin through NF-(kappa)B mediated induction of MT1-MMP. J Cell Sci 2001, 114:131-139.

62. Han YP, Nien YD, Garner WL: Tumor necrosis factor-alpha-induced proteolytic activation of pro-matrix metalloproteinase-9 by human skin is controlled by down-regulating tissue inhibitor of metalloproteinase- 1 and mediated by tissue-associated chymotrypsin-like proteinase. J Biol Chem 2002, 277:27319-27327.

63. Ferwerda $G$, Kullberg BJ, de Jong DJ, Girardin SE, Langenberg DM, van Crevel R, Ottenhoff TH, Van der Meer JW, Netea MG: Mycobacterium paratuberculosis is recognized by Toll-like receptors and NOD2. I Leukoc Biol 2007, 82:1011-1018.

64. Kojima Y, Kinouchi Y, Takahashi S, Negoro K, Hiwatashi N, Shimosegawa T: Inflammatory bowel disease is associated with a novel promoter polymorphism of natural resistance-associated macrophage protein 1 (NRAMP1) gene. Tissue Antigens 2001, 58:379-384.

\section{Pre-publication history}

The pre-publication history for this paper can be accessed here: http://www.biomedcentral.com/1471-230X/11/34/prepub

doi:10.1186/1471-230X-11-34

Cite this article as: Rath et al:: Presence of intestinal Mycobacterium avium subspecies paratuberculosis (MAP) DNA is not associated with altered MMP expression in ulcerative colitis. BMC Gastroenterology 2011 11:34.

\section{Submit your next manuscript to BioMed Central and take full advantage of:}

- Convenient online submission

- Thorough peer review

- No space constraints or color figure charges

- Immediate publication on acceptance

- Inclusion in PubMed, CAS, Scopus and Google Scholar

- Research which is freely available for redistribution

Submit your manuscript at www.biomedcentral.com/submit 